NBER WORKING PAPER SERIES

\title{
HOW WOULD MEDICARE FOR ALL AFFECT HEALTH SYSTEM CAPACITY? EVIDENCE FROM MEDICARE FOR SOME
}

\author{
Jeffrey Clemens \\ Joshua D. Gottlieb \\ Jeffrey Hicks \\ Working Paper 28062 \\ http://www.nber.org/papers/w28062 \\ NATIONAL BUREAU OF ECONOMIC RESEARCH \\ 1050 Massachusetts Avenue \\ Cambridge, MA 02138 \\ November 2020
}

This manuscript was prepared for Tax Policy and the Economy volume 35 (forthcoming 2021). Clemens and Gottlieb are grateful to the Stanford Institute for Economic Policy Research and the Federal Reserve Bank of San Francisco for their hospitality while working on this paper. Clemens and Gottlieb received support from the National Institute on Aging of the National Institutes of Health under Award Number P30AG012810 to the NBER. The content is solely the responsibility of the authors and does not necessarily represent the official views of the National Institutes of Health or of the National Bureau of Economic Research. Gottlieb also acknowledges the hospitality of the Einaudi Institute for Economics and Finance and support from SSHRC. We are grateful to Paul Beaudry, Michael Bohm, Nicole Fortin, David Green, Thomas Lemieux, Robert Moffitt (the editor), Craig Riddell, Dan Sacks, Hugh Shiplett, Munir Squires, our discussants Adam Shapiro and Ashley Swanson, and audiences at the University of Texas, AEA, Rome Junior Conference on Applied Microeconomics, Junior(ish) Health Economics Summit, IZA/SOLE, NTA, Tax Policy and the Economy, and UBC for valuable comments on an earlier version of this paper, and to Hao Li for research assistance.

NBER working papers are circulated for discussion and comment purposes. They have not been peer-reviewed or been subject to the review by the NBER Board of Directors that accompanies official NBER publications.

(C) 2020 by Jeffrey Clemens, Joshua D. Gottlieb, and Jeffrey Hicks. All rights reserved. Short sections of text, not to exceed two paragraphs, may be quoted without explicit permission provided that full credit, including $\odot$ notice, is given to the source. 
How Would Medicare for All Affect Health System Capacity? Evidence from Medicare for Some

Jeffrey Clemens, Joshua D. Gottlieb, and Jeffrey Hicks

NBER Working Paper No. 28062

November 2020

JEL No. H51,I11,I13

\begin{abstract}
Proposals to create a national health care plan such as "Medicare for All" rely heavily on reducing the prices that insurers pay for health care. These changes affect physicians' short-run incentives for care provision and may also change health care providers' incentives to invest in capacity, thereby influencing the availability of care in the long term. We provide evidence on these responses using a major Medicare payment change combined with survey data on physicians' time use. We find evidence that physicians increase their time spent on capacity building when remuneration increases, and that they are subsequently more willing to accept new patients--especially those who may be the residual claimants on marginal capacity. These forces imply that short-run supply curves likely differ from long-run supply curves. Policymakers need to account for how major changes to payment incentives would influence the investments that determine health system capacity.

Jeffrey Clemens

Department of Economics

University of California, San Diego

9500 Gilman Drive \#0508

La Jolla, CA 92093

and NBER

jeffclemens@ucsd.edu

Joshua D. Gottlieb

University of Chicago

Harris School of Public Policy

1307 E. 60th St.

Chicago, IL 60637

and NBER

jgottlieb@uchicago.edu

Jeffrey Hicks

Vancouver School of Economics

University of British Columbia

6000 Iona Dr

Vancouver, BC V6T 1L4

Canada

jeffrey.hicks@ubc.ca
\end{abstract}


Investments in a health system's capacity determine the amount of care it can provide. Countries and regions that have invested in more physicians and more hospital beds provide more care, as well as more intensive treatments, to their residents (Fisher et al., 2000). While this marginal care may not always be efficient, the Covid-19 pandemic reveals some important benefits from having these investments in place, even if high capacity is excessive under normal conditions (Fisher et al., 2003). To have capacity in place when it is needed, the health system's incentives must be conducive to forward-looking investments during ordinary times. So as policymakers consider proposals such as "Medicare for All," it is critical for them to consider what incentives such systems would create for these investments. We take up precisely this question.

At prevailing private-sector prices, government insurance for all 330 million Americans would likely be unaffordable. To achieve affordability, national health insurance proposals like Medicare for All have thus assumed significant reductions in payment rates to health care providers (Chown et al., 2019). Blahous (2018) estimates that provider payments would fall by 40 percent, or $\$ 384$ billion per year, under the version of Medicare for All proposed by Bernie Sanders. Schulman and Milstein (2019) suggest that such cuts would bring payment rates below hospitals' current costs, requiring them to make major operational changes to reduce their costs and remain solvent.

Lowering payments would undoubtedly save money in the short term. But what would it do to physicians' incentives to invest for the long term? Knowing they face lower payment rates, would they reduce investments in their practices, and hence in the health system's capacity? Existing evidence from the hospital and pharmaceutical industries suggests that payment rules influence investments in physical capital and innovation (Acemoglu and Finkelstein, 2008; Finkelstein, 2004; Acemoglu and Linn, 2004). But the health sector is intensive in labor and human capital. Physicians' investments in their human capital and entrepreneurial capital may be as consequential as traditional investments for how the mar- 
ket evolves. We study how a change in the level of government payments to physicians - such as that which Medicare for All would entail —influences these critical investment outcomes.

Existing research on physicians' responses to payment rates focuses on the number of services they provide (Clemens and Gottlieb, 2014) and the time they spend treating patients. An extensive, controversial literature argues for backward-bending labor supply — that when payment rates are cut, the supply of physician care expands. More recent work tends to find standard upward-sloping responses. ${ }^{1}$

We argue that both of these views miss an important element of physicians' decisions: how much to invest in future productivity. As the literature on human capital theory has long understood (Becker, 1962; Ben-Porath, 1967; Mincer, 1974a,b), overall work effort includes both revenue-generating activities and investments in human capital, which influence future productivity. These activities are just as important among physicians as elsewhere in the economy, and provide a natural channel by which government policy can influence the longrun supply of medical treatments.

We exploit time use data that divide physicians' overall working time into patient care hours, which generate revenues, and time spent on other medical activities. These other activities include the recruitment of new patients, investments in physicians' professional networks, and investments in continuing education, such as studying to maintain board certification. Some of these investments augment the physician's human capital while others build managerial capacity. Both set the stage for increases in care provision over longer time horizons and increase the physician's future earnings potential. We examine how such

\footnotetext{
${ }^{1}$ The classic cites on physician income effects include Rice and Labelle (1989), Rice (1983; 1984), Gruber and Owings (1996), Yip (1998), and Jacobson et al. (2013). McGuire and Pauly (1991) provide the canonical model and McGuire (2000) and Chandra et al. (2011) review this literature. The physician literature has also found evidence of standard upward-sloping labor supply, especially in more recent work (Gruber, Kim and Mayzlina, 1999; Hadley and Reschovsky, 2006; Clemens and Gottlieb, 2014; Alexander, 2015; Johnson and Rehavi, 2016; Brekke, Holmås, Monstad and Straume, 2017; Foo, Lee and Fong, 2017). Nevertheless, the traditional view, that physicians have backward-bending labor supply and offset payment cuts with increased volume, is embedded in policymaking (Codespote et al., 1998).
} 
investments and labor supply vary over a physician's career and in response to governmentinduced price shocks.

The Medicare policy shock we employ changed the price of physicians' output - that is, the care they provide - differentially across specialties. We find that a substantial reduction in reimbursements led physicians in adversely affected specialties to reduce their investment activities. They both allocate fewer hours to non-reimbursable activities and become less willing to accept new patients.

Notably, the decline in physicians' willingness to accept new patients is larger for Medicaid patients than for Medicare patients. This suggests that changes in capacity can significantly impact patients whose own payments may not change. At baseline, Medicaid is a less attractive payor than Medicare: it offers physicians lower rates, and requires more cumbersome paperwork (Gottlieb et al., 2018), so physicians are less likely to treat Medicaid beneficiaries (Dunn et al., 2020). If physicians prefer to treat patients with Medicare or private insurance, Medicaid patients may be the residual claimants on excess capacity. Even when an expansion is driven by Medicare rates, this could relax otherwise-binding capacity constraints and increase access to care for Medicaid patients.

Our results are consistent and complementary with existing evidence on investments in physical capacity. The literature finds that both hospitals' and physicians' capital investments respond positively to payment rates, consistent with standard profit maximization. Acemoglu and Finkelstein (2008), for instance, find that hospitals increase capital intensity and invest in new technologies when it is profitable to do so. In the physician context, Clemens and Gottlieb (2014) find that the overall level of Medicare payments influences physicians' treatment intensity and technology choices. ${ }^{2}$ In this paper, we find the same for

\footnotetext{
${ }^{2}$ Additional related work has considered the effects of reimbursements and other payments on the types of patients physicians choose to treat (Chen, 2014; Garthwaite, 2012; Baker and Royalty, 2000), the drugs they choose to prescribe (Carey et al., 2015), the number of staff members they hire (Buchmueller et al., 2016), on the location of their practices, in particular at early stages of their careers (Leganza et al., 2020), and whether they enter private practice and/or sub-specialize (Chen et al., 2018).
} 
physicians' investments in their careers. If these investments increase provider capacity in the future, overall health care supply responses can be very different in the short-run and long-run. Policy decisions based exclusively on the short-run responses would miss a crucial part of their impacts.

Physician behavior has broad implications for government spending and overall economic performance. In 2016, the United States spent $\$ 725$ billion, or 3.5 percent of GDP, on physician care and similar medical services alone. ${ }^{3}$ Recurrent concerns about physician shortages (Cooper et al., 2002; Staiger et al., 2009; Petterson et al., 2012) highlight the need to understand doctors' investments. Our analysis suggests that some aspects of physicians' investments in their careers may be quite responsive to government payment policies. While we are able to examine some important margins, others remain under-explored. More research is needed to understand how physicians choose their specialties, their locations, the structure of their practices, and the form of their human capital investments.

The remainder of the paper is structured as follows: Section 1 presents a conceptual framework for analyzing how reimbursements might shape the scale of physicians' practices. Section 2 describes the data we analyze, including our measures of on-the-job investments and labor supply. Section 3 demonstrates that the life cycle behavior of these measures is consistent with standard human capital theory. Section 4 introduces the Medicare policy change we analyze and describes our empirical strategy for identifying how investments and labor supply respond to pricing changes. Section 5 presents the results and section 6 concludes.

While market size is a different concept from payment levels, an increase in market size has a similar effect: it can increase the profitability of fixed investments. An important related literature studies this sort of shock, often using increases in insurance coverage. Finkelstein (2007) finds that hospitals' investments and even entry decisions depend on the number of patients in an area with generous insurance coverage. Finkelstein (2004) finds that investments in new vaccines respond to expected profitability of those investments. Acemoglu and Linn (2004), and a substantial subsequent literature, finds a similar result for pharmaceuticals. Clemens and Rogers (2020) find similar effects for prosthetic limbs.

${ }^{3}$ This comes from the "Physician and Clinical Services" component of the 2018 National Health Expenditure Data (Centers for Medicare and Medicaid Services, 2019). 


\section{A Conceptual Framework Connecting Reimburse- ment Rates to Investments in Physicians' Practices}

Our goal is to analyze how investments in physicians' practices respond to reimbursement rates. Outcomes of potential interest include a practice's capacity and the physician's willingness to see new patients in the future. These practice-level outcomes in aggregate determine market-wide capacity. We start by outlining a simple model of physician production and investment that provides a framework for interpreting the subsequent empirical analysis.

\subsection{Model with Investments in Physical Capital}

Consider an economy with two types of patients: $H$ and $L$. Group $H$ has generous insurance that pays a high reimbursement rate, $r_{H}$, such as Medicare or private insurance. Group $L$ has a lower-paying insurance with reimbursement of $r_{L}<r_{H}$, such as Medicaid. We abstract from negotiations over these rates and assume they are set administratively.

Total demand for health care includes $Q_{H}$ patients from group $H$ and $Q_{L}$ patients from group $L$. Since group $H$ offers a higher reimbursement rate, physicians compete with one another for patients in this group. They compete by investing in quality, which comes from their investments in productive capacity (Garthwaite et al., 2020). Capacity unused on high-paying patients can then be used for low-paying patients, and we assume that there are always enough such patients to consume any care that physicians offer them. We abstract away from choices of how much care to provide for each patient.

The investments we have in mind may be investments of time, as in canonical human capital models, or financial investments in physical capital. In this section, we develop key intuitions by analyzing a one period model with investments in physical capital. In contrast with time investments, for which costs depend on time spent on other workplace activities, the cost of investments in physical capital are denominated in dollars. This yields intuitive 
analytical results. In section 1.2 , we incorporate time investments that may pay off across multiple time periods.

Physician $j$ chooses a dollar-denominated investment in her practice's productive capacity, $i_{j}$, and the price of investment is normalized to one. The total variable cost of supplying $q=q_{H}+q_{L}$ units of care is $\theta\left(i_{j}\right) C\left(q_{H}+q_{L}\right)$ where $\theta(i)$ is a measure of productivity that physicians can improve through investments. We assume that $C$ is positive and convex, while $\theta(i)>0$ is decreasing and convex - more investment reduces marginal costs but increasing dollars of investment have decreasing effectiveness at reducing these costs. Finally, suppose that a physician investing $i_{j}$ in a market in which other physicians invest $i_{-j}$ obtains market share $s\left(i_{j}, i_{-j}\right)$ of the $Q_{H}$ high-paying patients. So the number of group $H$ patients available to this physician is $\bar{q}_{H}=s\left(i_{j}, i_{-j}\right) Q_{H}$. Presumably $\frac{\partial s\left(i_{j}, i_{-j}\right)}{\partial i_{j}}>0, \frac{\partial^{2} s\left(i_{j}, i_{-j}\right)}{\partial i_{j}^{2}}<0$, and $\frac{\partial s\left(i_{j}, i_{-j}\right)}{\partial i_{-j}}<0$. The physician must also decide on $q_{L}$, the number of low-paying patients to serve. The physician's profit is:

$$
\pi\left(i, q_{H}, q_{L}\right)=q_{H} r_{H}+q_{L} r_{L}-i-\theta(i) C\left(q_{H}+q_{L}\right)
$$

and her decisions can be described by maximizing this equation subject to the constraints:

$$
\begin{aligned}
& 0 \leq q_{H} \leq \bar{q}_{H} \\
& 0 \leq q_{L} \\
& 0 \leq i
\end{aligned}
$$

This problem has three different cases, depending on the number of high-paying patients available, which determines which constraints in (2) bind. In all cases, the physician can directly choose any nonnegative $q_{L}$, since we assume demand for care among group $L$ patients is unsatiated. The cases differ in how many group $H$ patients are available, relative to the 
number the physician would like to treat based on the reimbursement rate $r_{H}$ and cost curve. Denote by $\tilde{q}(i)$ this "ideal" number, which is defined as the point where $r_{H}=\theta(i) C^{\prime}(\tilde{q})$. The first two cases are defined by the relationship between $\tilde{q}(i)$ and the number of group $H$ patients available, $\bar{q}_{H}$.

\section{Case A}

The first case is when there are many group $H$ patients available, i.e. $\tilde{q}(i)<\bar{q}_{H}$. In this case, the following first-order conditions describe the maximum of (1):

$$
\begin{aligned}
\underbrace{r_{H}}_{\text {MR of high-paying patient }} & =\underbrace{\theta\left(i^{*}\right) C^{\prime}\left(q_{H}^{*}+q_{L}^{*}\right)}_{\text {MC of extra patient }} . \\
q_{L}^{*} & =0 \\
\underbrace{1}_{\begin{array}{c}
\text { price of } \\
\text { investment }
\end{array}} & =\underbrace{-\theta^{\prime}\left(i^{*}\right) C\left(q_{H}^{*}+q_{L}^{*}\right)}_{\begin{array}{c}
\text { cost savings on existing patients } \\
\text { (recall that } \left.\theta^{\prime}(i)<0\right)
\end{array}}
\end{aligned}
$$

In these first-order conditions, $i_{j}^{*}$ reflects the physician's optimal investment decision, $q_{L}^{*}$ reflects the physician's chosen number of group $L$ patients to treat, and $q_{H}^{*}$ is the number of group $H$ patients to treat. Note that, as long as $r_{L}<r_{H}$, and the physician can choose how many group $H$ patients to treat, she will not treat any group $L$ patients; the marginal cost is the same and group $L$ patients pay less. So, in this model, an unconstrained physician will always have $q_{L}^{*}=0$.

Figure 1 shows this case. The solid vertical line at $\bar{q}_{H}$ indicates the number of group $H$ patients available to the physician for a given level of investment $\left(i_{j}^{*}, i_{-j}^{*}\right)$. The dashed orange line at $q_{H}^{*}$ shows the number of group $H$ patients that the physician chooses to treat. In this case, $q_{H}^{*}=\tilde{q}(i)$; i.e., the physician treats up to the point where the marginal cost curve $C^{\prime}$ is equal to the high reimbursement rate, $r_{H}$. 


\section{Case B}

A second case arises when the market has fewer high-paying patients, but still enough to crowd out all of the low-paying patients. This is illustrated in Figure 2. Now the physician can't find enough group $H$ patients to satisfy equation (3). So she is at a corner solution for both group $L$ patients - of whom she won't treat any - and group $H$ patients, of whom she will treat as many as she can find, given her investment level. We can express this condition as $\tilde{q}^{\prime}(i)<\bar{q}_{H} \leq \tilde{q}(i)$, where $\tilde{q}^{\prime}(i)$ is defined by $r_{L}=\theta(i) C^{\prime}\left(\tilde{q}^{\prime}\right)$ and is the point below which she would begin treating some group $L$ patients.

Recall that the number of high-paying patients available depends on the physician's investment decision through $\bar{q}_{H}=s\left(i_{j}, i_{-j}\right) Q_{H}$. Using this formula in place of $q_{H}$ in equation (1), the optimality conditions are:

$$
\begin{aligned}
q_{H}^{*} & =\overline{q_{H}}=s\left(i_{j}^{*}, i_{-j}\right) Q_{H} \\
q_{L}^{*} & =0 \\
1 & =\underbrace{s^{\prime}\left(i_{j}^{*}, i_{-j}^{*}\right) Q_{H}\left[r_{H}-\theta\left(i^{*}\right) C^{\prime}\left(q_{H}^{*}+q_{L}^{*}\right)\right]}_{\text {Net profit of group } H \text { patients attracted by investment }}-\underbrace{\theta^{\prime}\left(i^{*}\right) C\left(q_{H}^{*}+q_{L}^{*}\right)}_{\begin{array}{c}
\text { cost savings on existing patients } \\
\text { (recall that } \left.\theta^{\prime}(i)<0\right)
\end{array}}
\end{aligned}
$$

We assume throughout that each physician is small relative to the market, so we can assume away strategic interactions. Thus physician $j$ takes other physicians' investment decisions $i_{-j}^{*}$ as given. The first order condition for investment now equates the cost of investment (normalized to 1) with two gains: the net gain from attracting additional high-paying patients and the reduction in unit costs on existing patients.

In Figure 2, the dashed line at $\tilde{q}$ indicates the number of group $H$ patients the doctor would like to treat - that is the point where the reimbursement rate equals marginal costs. Since there are fewer high-paying patients available than she would like to treat, she practices at the corner solution where $q_{H}^{*}=\bar{q}_{H}=s\left(i_{j}^{*}, i_{-j}\right) Q_{H}$ and she treats all available group $H$ 
patients. She could increase market share by increasing investment in order to reach $\tilde{q}$, and conceivably even move to Case A, but does not because the extra profits from increasing productivity and market share are lower than the cost of investment.

\section{Case C}

The final case may be the most interesting. When $\bar{q}_{H}<\tilde{q}^{\prime}$, the physician treats all available group $H$ patients and also some from group $L$. In this case, the relevant first-order conditions are those for her two choice variables, $i$ and $q_{L}$ :

$$
\begin{aligned}
q_{H}^{*} & =\overline{q_{H}}=s\left(i_{j}^{*}, i_{-j}\right) Q_{H} \\
\underbrace{r_{L}}_{\substack{\text { MR of group } L \\
\text { patients }}} & =\underbrace{\theta\left(i^{*}\right) C^{\prime}\left(s\left(i_{j}^{*}, i_{-j}^{*}\right) Q_{H}+q_{L}^{*}\right)}_{\text {MC of extra patient }} . \\
1 & =\underbrace{s^{\prime}\left(i_{j}^{*}, i_{-j}^{*}\right) Q_{H}\left[r_{H}-\theta\left(i^{*}\right) C^{\prime}\left(q_{H}^{*}+q_{L}^{*}\right)\right]}_{\text {Net profit of group H patients attracted by investment }}-\underbrace{\theta^{\prime}\left(i^{*}\right) C\left(q_{H}^{*}+q_{L}^{*}\right)}_{\begin{array}{c}
\text { cost savings on existing patients } \\
\text { (recall that } \left.\theta^{\prime}(i)<0\right)
\end{array}}
\end{aligned}
$$

Now $q_{L}^{*}$ is an interior solution and reflects the physician's chosen number of group $L$ patients to treat, where the reimbursement $r_{L}$ rate equates to the marginal cost of care. As before, the first order condition for investment equates the cost of investment (normalized to 1) with two gains, the first from attracting more high-paying patients and the second from reductions in unit costs. Appendix A.1. establishes high-level conditions on functional forms such that these first-order conditions yield a unique allocation.

Figure 3 illustrates this case. With $\bar{q}_{H}$ below $\tilde{q}^{\prime}$, the physician treats some group $L$ patients. The physician will treat all $\bar{q}_{H}$ high-paying patients available, plus the optimal number of group $L$ patients, $q_{L}^{*}$.

All three cases are likely to be relevant in some empirical contexts; many physicians don't treat Medicaid patients while others do (Dunn et al., 2020), and some appear to be at interior 
solutions while others are at corners (Brekke et al., 2017; McKnight, 2007). Because we want to understand the impact of investment on Medicaid patients - and since the empirical work will suggest that this is the relevant case - we focus on Case C.

\section{Effects of Reimbursement Rate Changes and Demand Shocks}

Focusing on Case $\mathrm{C}$, we now consider the key comparative statics of changes in reimbursement rates. An increase in the reimbursement rates for high-paying patients heightens each physician's desire to compete for a larger share of the high-paying market. Panel A of Figure 4 illustrates this incentive. Increasing the number of high-rate clients available to the physician, from $q_{H}$ to $q_{H}^{\prime}$, directly increases revenue by $\left(q_{H}^{\prime}-q_{H}\right)\left(r_{H}-r_{L}\right)$. This extra revenue accrues as the physician swaps low-rate clients for high-rate clients. When $r_{H}$ increases to $r_{H}^{\prime}$, this incentive to acquire high-rate patients rises by $\left(q_{H}^{\prime}-q_{H}\right)\left(r_{H}^{\prime}-r_{H}\right)$, as illustrated by the blue rectangle. It follows that starting from an equilibrium with $r_{H}$, raising the rate to $r_{H}^{\prime}$ will cause physician $j$ to invest more (holding constant, for now, other physicians' responses).

In addition to increasing physician $j$ 's market share, the higher level of investment lowers her marginal cost. The shaded green area between the two marginal cost curves represents the gains from reduced costs of treating patients. Due to reductions in marginal costs, physicians may be willing to serve more low-paying patients. This is illustrated by the new intersection between marginal cost and $r_{L}$, where the total number of patients is now $q_{H}^{\prime}+q_{L}^{\prime}$. The net impact on group $L$ patients from any one physician is unclear: some of them are displaced by group $H$ patients, while others benefit from the overall expansion of supply.

We now turn to what happens at the level of the market as a whole. If physicians' practices are symmetric, the increase in the reimbursement rate will lead to an increase in overall productive capacity (due to reductions in unit costs for all physicians), but no actual changes in the number of high-paying patients each physician serves. When all physicians 
are in Case $\mathrm{C}$, they are treating as many group $H$ patients as they can. Since all group $H$ patients were already being treated, and there is no scope to increase the aggregate number of group $H$ patients, all of the growth of any one physician's group $H$ patients is a business stealing effect. In this setting, the higher investment is guaranteed to translate to more health care provided to low-paying patients. Low-paying patients are the residual claimants on the additional productive capacity generated by high-paying sources of insurance coverage.

The size and distribution of the business stealing effect is less obvious. Panel B of Figure 4 shows what happens to physician $j$ when her competitors increase investment, as they are likely to do in a response to an increase in $r_{H}$. If physician $j$ does not also invest, she will lose at least some of her group $H$ revenue. This is illustrated by the combination of the larger green rectangle to the left and the red area between $r_{H}^{\prime}$ and $r_{H}$. Maintaining her initial market share will thus require physician $j$ to invest, which increases her capacity for group $L$ patients. The net effect depends on the exact shape of the market share function $s(\cdot, \cdot)$ and the distribution of responses across her competitors. So long as all group $H$ patients were being treated at baseline, however, the supply of care to group $L$ patients will rise unambiguously following an increase in the high-paying patients' reimbursement rate.

We next consider how the market responds to an influx of demand, perhaps due to a pandemic. A pandemic results in an increase in the number of individuals in need of care. We model the pandemic as a multiplier, $\alpha>1$, on the number of individuals desiring care. Now the physician can treat $\alpha \bar{q}_{H}$ high-paying patients, as illustrated in Figure 5. Physicians will begin, as before, by serving as many high-paying patients as they can. The pandemic will thus tend to reduce care access for low-paying patients. Note that a health system that had high levels of capacity, due to high reimbursements for high-paying patients, will be better positioned to weather the pandemic while maintaining more supply for low-paying patients. 


\subsection{Model with Time-Intensive Investments in Human Capital}

We next analyze the effects of reimbursement rates on investments that require the physician's time. Time investments are central in canonical models of human capital accumulation. They also map quite directly into one of our primary outcomes of empirical interest. We generalize physicians' welfare to:

$$
\begin{aligned}
U\left(\left\{\pi\left(i, q_{H}^{j}, q_{L}^{j}\right), q_{H}^{j}, q_{L}^{j}\right\}_{j=1,2}, i\right)= & \pi\left(i, q_{H}^{1}, q_{L}^{1}\right)+v\left(i+\gamma(i)\left(q_{l}^{1}+q_{h}^{1}\right)\right) \\
& +\beta\left[\pi\left(i, q_{H}^{2}, q_{L}^{2}\right)+v\left(\gamma(i)\left(q_{l}^{2}+q_{h}^{2}\right)\right)\right] .
\end{aligned}
$$

Equation (12) modifies equation (1) in two key ways. First, the first period cost function includes the sum of investment time $i$ and productivity-adjusted treatment time $\left(\gamma(i)\left(q_{l}^{1}+q_{h}^{1}\right)\right)$. Second, equation (12) includes a second time period during which first period investments continue to pay off through productivity in treating patients, $\gamma(i)$.

In Appendix A, we derive the conditions describing the physician's optimal choice of investment time and time spent treating low-paying patients. We continue to focus on Case $\mathrm{C}$ from above, defined as before to involve an interior solution with non-zero time spent treating low paying patients. The key intuitions from the simpler model of dollardenominated investments carry through.

As in the previous section, increases in the reimbursement for treating high-paying patients result in increases in investment. This is driven, once again, by the increased return to obtaining a larger share of the high-paying patient pool. In the extended model, this benefit materializes in both the first and second time periods. Note that this return, which arises from competition for high-paying patients, breaks the classic Ben-Porath (1967) result that wages don't affect the life cycle investment pattern. This is because the opportunity cost of investment time comes from treating a low-paying patient, while the return comes from the 
competition for high-paying patients.

As before, an increase in investment time reduces marginal costs, which will tend to increase physicians' willingness to serve low-paying patients. With two periods, a rise in $\tau_{H}$ is more likely to increase $q_{L}$ because the investment response is larger than in a single period model. This expansion of care to group $L$ is most likely in the second period because the marginal cost curve of patient care is flatter in period two since no time is lost to investment ( $v$ is convex).

\section{Measuring Physicians' On-the-Job Investments and Labor Supply}

We use data from the Community Tracking Study (CTS) to study physicians' investment and labor supply behavior. The CTS measures a variety of characteristics of physicians' practices and time use, and was conducted over four two-year waves: 1996/97, 1998/99, 2000/01, and 2004/05. In each wave, the CTS surveyed roughly 12,000 physicians across 60 randomly chosen geographic areas (Center for Studying Health System Change, 1999). We use the restricted-use data, which contain detailed responses to certain questions, plus a linked identifier that allows us to create a panel of physicians. ${ }^{4}$ The survey focuses on physicians whose primary focus is direct patient care; research and federally-employed physicians are excluded, as are specialties not providing direct patient care. We examine three measures of investment behavior:

Non-Patient Hours: Physicians report their weekly total medical hours and the time spent providing direct patient care. We define non-patient hours as the difference between total and patient care hours. To clarify the substance of this measure, we present the exact wording of the questionnaire that is used to elicit time allocation. For total hours, the survey

\footnotetext{
${ }^{4}$ Each wave contains a subset of respondents from the previous wave, resulting in an unbalanced panel. Appendix Table B.2 shows that observable characteristics are balanced across individuals of differing panel lengths.
} 
asks:

Thinking of your last complete week of work, approximately how many hours did you spend in all medically related activities? Please include all time spent in administrative tasks, professional activities and direct patient care. Exclude time on call when not actually working.

For patient care hours, respondents are asked:

Thinking of your last complete week of work, about how many hours did you spend in direct patient care activities? (If necessary, read:) INCLUDE time spent on patient record-keeping, patient-related office work, and travel time connected with seeing patients. EXCLUDE time spent in training, teaching, or research, any hours on-call when not actually working, and travel between home and work at the beginning and end of the work day.

The residual measure of non-patient hours therefore includes training, professional activities, and only administrative work unrelated to direct patient care. ${ }^{5}$ This includes obtaining or maintaining board certification, recruiting patients, building professional relationships, attending conferences, staying apprised of new treatment procedures, adopting and implementing new physical capital, remaining compliant with evolving medical regulations, hiring and managing employees, and building overall organizational capacity within one's practice. Each of these endeavors contribute towards individual human capital and broader practice capacity over the long run. So we adopt this broad definition of non-patient hours as ongoing investments throughout the paper.

Board Certification: Physicians can obtain board certifications in their primary specialty and sub-specialties, neither of which is legally required to practice medicine. Instead, these

\footnotetext{
${ }^{5}$ Research is unlikely to constitute a meaningful component of non-patient hours because the CTS explicitly excludes doctors focused on research from its samples. The questionnaire wording also excludes from non-patient hours the time physicians spend on-call but not actually working.
} 
certifications may act as a signal of quality, making the physician more attractive to potential clients or employers. ${ }^{6}$ Obtaining board certification entails fees ranging from $\$ 1,000$ to $\$ 3,000$ (Drolet and Tandon, 2017), an initial written and oral exam, re-certifying exams at intervals of 6-10 years, and other maintenance of certification requirements. ${ }^{7}$ Given certification's voluntary nature, and the associated time and monetary costs, it proxies effectively for ongoing investments in practice capacity. Appendix Figure B.1 provides evidence that physicians with board certification have higher earnings than physicians without board certification. ${ }^{8}$ This confirms that, at least as a matter of correlation, the continuing education associated with board certification predicts higher incomes. ${ }^{9}$

Willingness to Accept New Patients: Respondents report their willingness to accept new patients, on a four point integer scale, for each type of patient: Medicare, Medicaid, and privately insured. We construct a summary index by adding together the response for each patient type, and rescaling such that it ranges from zero to one. One indicates a complete willingness to accept new patients of any type, and zero a complete refusal. Building and maintaining a customer base is one form of ongoing investment physicians often must make to ensure current and future profitability. As such, a physician's desire to accept new patients proxies for ongoing investments, and in turn, long-term care supply. ${ }^{10}$

\footnotetext{
${ }^{6}$ In a survey of internists, Lipner et al. (2006) find that a majority of those maintaining certification report doing so for "positive professional reasons," with a minority reporting that certification is required by an employer.

${ }^{7}$ Maintenance of certification (MOC) often entails online training modules in medical knowledge or activities that are supposed to improve patient quality. For instance, the American Board of Internal Medicine requires physicians to earn 100 points every five years, by undertaking either online training modules, or "Quality Improvement/Practice Improvement" activities, each of which typically garners 10-20 points. MOCs became a regular part of certification beginning in the early 2000s.

${ }^{8}$ This holds both within age groups and when examining surgeons or non-surgeons separately.

${ }^{9}$ Cassel and Holmboe (2008) provide a history and overview of board certifications. The evidence is mixed on whether certification affects clinical outcomes, health care costs, or other aspects of care. Lipner et al. (2013) provides an overview of some of this research, largely correlation-based, and concludes that there are positive correlations between board certification and knowledge, practice infrastructure, and communication. Conversely, Gray et al. (2014) and Haynes et al. (2014) find no effect of MOC requirements or re-certification, respectively, on clinical outcomes.

${ }^{10}$ Appendix C.2 discusses the details of the original question and how we rescale it.
} 
In addition to on-the-job investment measures, we examine income-generating patient care hours, total labor supply, and annual income:

Patient Care Hours: As described above, patient care hours involve direct face-to-face time with patients, patient record-keeping and related office work, and travel time connected with seeing patients. These are the activities that generate revenue for a practice. ${ }^{11}$

Total Labor Supply and Income: We measure total labor supply as the time spent on all medically-related activities. This is the sum of patient care hours and non-patient hours. Respondents also report their total income net of expenses for the year preceding the survey wave. So in the 1996/97 survey wave, income is requested for the 1995 calendar year. ${ }^{12}$

The restricted-use CTS data provide each respondent's primary specialty at a detailed level - specifying 126 unique specialties - as opposed to the aggregated categories available in the public-use version. This allows us to leverage disaggregated variation in Medicare reimbursement rates across specialties. Similarly, income in the restricted-use data is reported to the nearest $\$ 1,000$, while the public-use version reports income in $\$ 50,000$ bins. Appendix Tables B.1 and B.2 show summary statistics for the variables discussed above, and for additional variables that describe physicians' practice types.

\section{$3 \quad$ Life Cycle Patterns of Human Capital Investments}

Figure 6 shows cross-sectional life cycle patterns for time-use, willingness to take new patients, board certification, and annual income. After modest upticks early in physicians' careers, the investment activities we track decline nearly monotonically with age. This lines up with theoretical predictions (Ben-Porath, 1967), since the horizons over which investments

\footnotetext{
${ }^{11}$ Patient care hours are an imperfect proxy for the supply of medical care. For a given amount of time, a more efficient doctor can supply more medical care. Thus variation across doctors in treatment hours may understate variation in medical care supply. Medical care is also vaguely defined. Time spent answering patients' questions may not constitute medical treatment in the strict sense, but does improve the quality of service provided.

${ }^{12}$ The questionnaire phrasing for income is reported in Appendix C.2.
} 
pay off decline with age, and the opportunity cost of time increases when productivity is high.

On average, physicians in their late 30s spent just over 11 hours per week on non-patient hours. This level persists for a number of years until falling to just over 9 hours per week among those in their late 50s and early $60 \mathrm{~s}$. While the gradient is not steep, the pattern is clear: physicians gradually devote less time to medical activities other than patient care as they approach retirement. By comparison, patient care hours hit a high mark during the same age, but do not begin a strong descent until age 60. That non-patient hours decline earlier than revenue-generating patient hours is consistent with on-the-job investments being crowded-out when the time horizon for investments to payoff is shorter.

The willingness to take new patients also decreases nearly monotonically with age. Our measure declines from just under 0.8 for physicians 29-39 years old to 0.72 for doctors 65 or older. Because most physicians report taking "all" or "most" new patients of all insurance types, the index's range is modest. The decline we observe from the youngest physicians to the oldest physicians is equivalent to 1 standard deviation of the index. To the extent that a patient relationship is an ongoing commitment, this signals a desire to decrease practice activity both in the present and in the future.

Board certification follows a similar trajectory. Figure 6 Panel D shows that 90 percent of physicians in their late 30s and early 40s are board certified. The share falls to 80 percent among those in their early 50s, 70 percent among those in their early 60s, and 60 percent among older physicians. Maintaining board certification, which maps quite directly into the time investments contemplated by theory, thus matches the predictions well. That said, board certification rates have risen over time, which would contribute to the observed age gradient if younger doctors are leading the trend. Furthermore, a precondition for declining certification rates in old age is the ability to lose one's certification. However, a segment of the CTS sample hold lifetime certifications which are exempt from re-certification requirements. 
For both these reasons, the age profile of board certification should be interpreted with caution. We discuss robustness of the life cycle profiles in Appendix B.1.

The returns to investments in physicians' practices and human capital may accrue over a variety of different time horizons. So it is not clear which age groups should be most sensitive to the expected returns from these different investment activities. As a signal of quality, for example, board certification may generate returns by both increasing a physician's capacity to recruit new patients and improving her bargaining position in negotiations with private insurers. While improved bargaining position may be valuable through the last years of a physician's career, the need to recruit new patients may decline in advance of retirement. The precise timing with which the return to board certification might fall below its costs is thus unclear and may vary substantially across physicians.

The remaining panels of Figure 6 show life cycle profiles for total hours, patient care hours, and income. All three exhibit an inverse U-shape. Total hours peak between age 40 and 50, and then begin a steady decline. Patient care hours peak around age 40, remain steady until age 60, then trend downwards. Finally, income follows the trajectory of labor supply. It rises until age 50, then begins to decline. Consistent with a point made early by Heckman (1976), declines in earnings are driven in no small part by declines in labor supply.

Age is an imperfect measure of career horizon. To further support our interpretation that non-patient hours reflect ongoing investments, we leverage the panel component of the CTS to measure the decline in non-patient hours as physicians approach their year of attrition from the panel. ${ }^{13}$ The survey does not explicitly measure retirement, but Appendix Figure B.2 shows that attrition increases steeply with age, from a base hazard rate of 40-45 percent for mid-career doctors, to 60 percent for old physicians. The steady increase in attrition rates with age suggests that attrition from the panel among older physicians is partially

\footnotetext{
${ }^{13}$ Only the restricted-use version of the CTS provides physician identifiers, enabling us to exploit the panel component.
} 
attributable to retirement.

To quantify the relationship between retirement hazard and investment decisions, we estimate the following descriptive regression:

$$
\begin{aligned}
& y_{i t}=\alpha_{0}+\alpha_{2} \cdot\left(\text { Two Years Before } \text { Attrition }_{i t}\right)+\alpha_{4} \cdot\left(\text { Four Years Before Attrition }_{i t}\right) \\
& +\alpha_{8} \cdot\left(\text { Eight or More Years Before } \text { Attrition }_{i t}\right) \\
& +\psi \text { Surgeon }_{i}+\varphi_{a, s} \text { Age }_{i t} \times \text { Surgeon }_{i}+\epsilon_{i t}
\end{aligned}
$$

The outcome variable $y_{i t}$ in equation (13) is non-patient hours, either in levels or as a share of total hours, for physician $i$ of specialty $s(i)$ in survey wave $t$. We include a fixed effect $\psi$ for whether a physician is classified as a Surgeon or Non-Surgeon based on the CTS classification, and differential age fixed effects $\varphi_{a, s}$ for Surgeons and Non-Surgeons. ${ }^{14}$ The estimates of interest are the fixed effects for years-to-attrition. The base group is physicians in their final period in the sample. So the coefficients $\hat{\alpha}_{2}, \hat{\alpha}_{4}$, and $\hat{\alpha}_{8}$ estimate the differences in investment levels for physicians 2,4 , or $\geq 8$ years prior to attrition, relative to those making their final appearance. If attrition partly reflects retirement, and investments decline in the years approaching retirement, then the estimates should be positive, and declining towards zero as the physician approaches attrition. ${ }^{15}$

Figure 7 plots the estimates of how years-to-attrition relate to non-patient hours, both in levels and as a share of total working hours. Both hours measures decline monotonically as an

\footnotetext{
${ }^{14}$ Allowing age fixed effects to vary with specialty assuages concerns that the decrease as physicians approach retirement is driven by differing retirement patterns and different levels of non-patient hours between Surgeon and Non-Surgeons.

${ }^{15}$ The four waves of the CTS took place in 1996/97, 1998/99, 2000/01, and then 2004/05. The gap between waves 3 and 4 slightly complicates the analysis of behavior in the years leading up to attrition from the sample, as estimated in equation (13) and plotted in Figure 7. To deal with the gap, we use the structure of fixed effects shown in equation (13): 2,4 , and $\geq 8$ years prior to attrition. The first two fixed effects are in 2-year intervals due to the bi-annual frequency of the CTS. The final fixed effect is for 8 or more years because the difference between third and final CTS wave was 4 years (2000/01 to 2004/05). To avoid confounding the interpretation of the fixed effects, we restrict the sample to (i) all individuals observed in the first wave, and (ii) individuals who initially appeared in the second wave, but drop out of the sample before the final wave.
} 
individual approaches her final year in the panel. This is consistent with the interpretation of these non-patient hours as activities that contribute to the physician's long-run earnings capacity. Some of these activities, like the continuing education required to maintain board certification, can be described as classic investments in human capital. Others, like time spent cultivating new patient relationships, may more generally set the stage for continued work in future periods. We will emphasize these interpretations throughout the rest of the paper.

Figure 7 also shows that the decline in investments prior to attrition only holds for physicians aged 60 or greater. For physicians younger than 45, non-patient hours do not vary with years to attrition. ${ }^{16}$ So Figure 7 also suggests that higher attrition rates among older doctors reflect retirement decisions to a much greater extent than among mid-career physicians.

\section{Empirical Model for Testing Comparative Statics}

Having traced out the basic life-cycle pattern of physicians' investment activities, we next analyze how these investments respond to changes in their expected returns. We rely on a large Medicare reimbursement change that took place in 1998 and was not reversed. In order to reduce payment discrepancies and support primary care, Congress eliminated a policy that had increased reimbursements per unit of effort for surgical procedures relative to non-surgical services. This change reduced payments for all procedures by 10.4 percent while increasing payments for non-procedural services by an average of 5 percent. ${ }^{17}$ Because this change was almost simultaneously adopted by many private insurers (Clemens and Gottlieb,

\footnotetext{
${ }^{16}$ Appendix Figure B.5 shows a similar pattern for total hours worked and patient care hours. Appendix Figure B.6 reveals a similar pattern for certification status, while physicians' propensity to take new patients is flat over the years immediately preceding retirement.

${ }^{17}$ Clemens and Gottlieb (2017) present a more detailed description of the institutional history and decisionmaking behind this payment change. In Appendix Figure B.3, we show how the payment rates per unit of effort (called "Conversion Factors") evolved for surgical and non-surgical care during this time period.
} 
2017), the effect on the average prices - and hence hourly wages - for surgeons relative to non-surgeons was substantial. ${ }^{18}$ Forward-looking physicians would thus have anticipated a large and persistent change in the returns to practicing in surgery-intensive specialties relative to other specialties.

We adapt Clemens and Gottlieb's (2017) approach to analyzing this payment shock to more fully exploit the resulting variation in payments across physician specialties. The payment change applies at the level of each individual service - so an office visit experiences a price increase, while a cataract surgery would face a price decline. Since many specialties provide a combination of procedural and non-procedural services, each specialty's overall price change reflects the share of procedures in its output mix.

To estimate specialty-level average payment changes, we rely on data from the Physician/Supplier Procedure Summary (PSPS) file released by the Centers for Medicare and Medicaid Services. This file reports state-level aggregate data on Medicare's purchases of care from physicians and other professional suppliers at the service line level. For each state and individual medical service, the file reports how many services Medicare purchased and how much it spent. To estimate the overall percent change in payments by specialty, we look at each specialty's composition of services as of 1997. We take a weighted average of the Conversion Factor change, where each specialty's weight depends on the share of Medicare spending that comes from surgical procedures. Denote this weighted average by $\Delta p_{s(i)} \cdot{ }^{19}$ These values, reproduced in Table 1, provide a specialty-level payment shock and hence wage shock for forty-six different specialty groups. We use the specialty-level payment change to estimate two types of regressions. The first is a dynamic difference-in-differences

\footnotetext{
${ }^{18}$ The 1998/99 CTS began in August 1998, well after the policy's announcement and implementation.

${ }^{19}$ An alternative estimate is provided by Congressional Research Service (1998) in Table 2. They provide two estimates of the percent change in payments by specialty: one that only incorporates the Conversion Factor change, and one that also accounts for contemporaneous changes in the weights (Relative Value Units) assigned to different procedures. Our results are quite similar when using either the Congressional Research Service (1998) estimates or our own calculations.
} 
specification:

$$
\begin{aligned}
y_{i t}= & \beta_{98-99} \Delta p_{s(i)} \times \mathbb{1}_{t=1998-99}+\beta_{00-01} \Delta p_{s(i)} \times \mathbb{1}_{t=2000-01}+\beta_{04-05} \Delta p_{s(i)} \times \mathbb{1}_{t=2004-05} \\
& +\phi_{i} \mathbb{1}_{i}+\phi_{98-99} \mathbb{1}_{t=1998-99}+\phi_{00-01} \mathbb{1}_{t=2000-01}+\phi_{04-05} \mathbb{1}_{t=2004-05}+\varepsilon_{i t} .
\end{aligned}
$$

The unit of observation for this regression is the physician $(i)$-by-survey wave $(t)$; in other words, each observation in this regression is one survey response ( $N=31,760$ in our baseline regression). Each physician reports her specialty $s(i)$ and the main regressor of interest is that specialty's Medicare price change $\Delta p_{s(i)}$ interacted with survey wave fixed effects. Physician fixed effects are denoted by $\mathbb{1}_{i}$ and time fixed effects by $\mathbb{1}_{t}$ for each wave $t$. By including physician fixed effects, we use only variation in outcomes within a physician. The omitted time category is the 1996/97 survey wave prior to the policy change; as this is the only wave of the CTS prior to the policy change, we cannot separately estimate pre-trends. The resulting coefficients $\hat{\beta}_{98-99}, \hat{\beta}_{00-01}$, and $\hat{\beta}_{04-05}$, which we will present graphically, are our estimates of how the price change impacts physicians' choice of the outcome variable $y_{i t}$ in each time period after the change. We estimate all regressions using survey weights that account for the CTS sampling design, ${ }^{20}$ and cluster standard errors at the individual (panel unit) level to account for auto-correlation of individual-level shocks.

We also estimate a pooled regression that combines all of the post-implementation survey

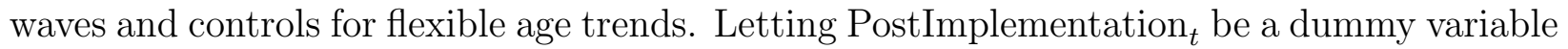
indicating $t \geq 1998$, we estimate:

$$
\begin{aligned}
y_{i t}= & \beta \Delta p_{s(i)} \times \text { PostImplementation }_{t}+\xi_{s} \mathbb{1}_{i} \\
& +\phi_{98-99} \mathbb{1}_{t=1998-99}+\phi_{00-01} \mathbb{1}_{t=2000-01}+\phi_{04-05} \mathbb{1}_{t=2004-05}+\varepsilon_{i t} .
\end{aligned}
$$

\footnotetext{
${ }^{20}$ The survey over-samples primary care physicians and some regions.
} 


\section{$5 \quad$ Empirical Results}

\subsection{Baseline Results on Investment Margins}

Figure 8 shows the dynamic results we obtain from estimating equation (14) at the individual level (physician-by-CTS wave). In each panel, 1996/97 is the omitted base year. Subsequent dots indicate the coefficient for survey waves after the price change, and blue bars indicate the 95 percent confidence interval. We find that payment increases lead to increased non-patient hours (panel B) and increases in the propensity to accept new patients (panel D). The estimates are larger over the medium run than over the short run. In contrast, Panel A shows no change in patient care hours. The effect on total hours in panel E is the sum of the effects on patient and non-patient hours, and is positive in 2000/01 but close to zero otherwise.

Panel $\mathrm{C}$ examines the effect on board certification. Certification may respond to the payment shock via changes in initial certification or via propensities to re-certify. The effect of the price change on these margins is identified by the just over 700 changes in certification status we observe within a physician in the CTS sample. ${ }^{21}$ Using this variation, we find no effect of the Medicare price shock on the propensity to be board certified.

Figure 9 checks whether physicians and specialties that increase their non-patient hours tend to simultaneously reduce their patient care hours. Panel A shows a binned scatterplot estimated at the individual physician level, while Panel B aggregates to the specialty level. We indeed find a strong negative relationship between changes in patient care hours and non-patient hours. This suggests that, rather than increasing overall labor supply as the target-income hypothesis would suggest, doctors facing payment cuts reallocate time from investments towards current earnings.

The CTS reports two variables for which we can assess the potential relevance of pre-

\footnotetext{
${ }^{21}$ Just over 500 of these changes are switches from not-certified to certified
} 
existing trends: net income and annual weeks worked. These variables are reported for the years prior to the respective survey waves: 1995, 1997, 1999, and 2003. This provides two pre-periods and two post-periods surrounding the 1998 policy change. Panels A and $\mathrm{B}$ of Figure 10 show the dynamic responses of these variables around the payment change by estimating equation (14)'s dynamic difference-in-differences model with 1997 as the base period. $^{22}$ Changes in weeks of work from 1995 to 1997 exhibit no correlation with the payment changes enacted in 1998 (panel B), while changes in income were modestly positively correlated with the subsequent payment changes (panel A). Given the absence of a clear pattern in these results, it is difficult to know with certainty how these findings might extend to the outcomes on which we focus.

We now turn to pooled results that combine all post-implementation waves into a single period. Each panel in Table 2 reports the coefficient estimates $\hat{\beta}$ from equation (15) for the same four outcome variables and 95 percent confidence intervals. The coefficient should be interpreted as a semi-elasticity, as it relates a percentage change in Medicare reimbursements (on the right-hand side) to the level of an outcome (such as, in Panel A, patient care hours). The table also reports the sample means of the outcome variables in the pre-policy period and uses them to convert the estimates to elasticities.

The statistically insignificant coefficient of 5.54 in column 1 implies that a ten percent increase in prices increases total hours worked per week by 0.54 , corresponding to an elasticity of 0.102 . We can rule out elasticities greater than 0.23 and smaller than -0.03 . Columns 2 and 3 show that this increase is driven by an increase in non-patient hours. We estimate elasticities of -0.0009 for patient hours and 0.49 for non-patient hours, suggesting moderate increases in the time physicians spend on activities that build their ongoing capacity.

Columns 4 and 5 show that physicians also become more willing to take new patients when

\footnotetext{
${ }^{22}$ For these regressions, we restrict to physicians that had been practicing for at least two years as of the survey because the measures of weeks worked and annual income are lagged by one to two years.
} 
prices rise. We estimate that a 10 percent increase in prices results in a 0.016 point increase in our index (from 0 to 1 ) of physicians' willingness to take new patients, corresponding to an elasticity of 0.218 . In contrast, there is no effect on the probability of holding board certification.

Economic theory makes it quite natural to find upward-sloping supply responses to Medicare payments. But it is less obvious how increased payment rates for Medicare patients will influence treatment for lower-paying patients, such as those insured by Medicaid. Medicaid pays less than Medicare, and imposes significant hassle on physicians as well, making them less likely to treat Medicaid beneficiaries. This characterization is supported by crosssectional patterns in physicians' behavior. Using both the CTS and the National Ambulatory Medical Care Survey (NAMCS), ${ }^{23}$ we examine physicians' reported willingness to see new Medicaid patients and the time they spend with patients during office visits. As Table 3 shows, physicians in both surveys report a much lower willingness to see new Medicaid patients relative to either Medicare or privately insured patients. Among those seen, physicians also spend less time with Medicaid patients, both unconditionally and conditional on underlying diagnoses. Oostrom et al. (2017) also find longer waiting time for Medicaid patients before office visits, especially where Medicaid rates are lower.

This descriptive evidence suggests that Medicaid patients can likely be considered the residual claimants on spare capacity: providers may be unlikely to expand capacity specifically for Medicaid patients, but nevertheless willing to use existing spare capacity for this population. So when Medicare payments drive a capacity expansion, this subsequent relaxation of capacity constraints may incidentally benefit Medicaid patients. In addition, higher incomes could have a direct impact on physicians' desire to provide care altruistically.

\footnotetext{
${ }^{23} \mathrm{NAMCS}$ is a CDC survey of office-based physicians, not employed by the federal government, and principally engaged in patient care. Our sample includes 4,502 physicians between 2003 to 2006 . Before 2003, NAMCS did not include survey questions related to physicians' willingness to accept new patients. We therefore limit the sample to the years 2003 to 2006 to overlap with the later years of the CTS.
} 
To examine these possibilities, Table 4 decomposes the types of new patients that physicians are willing to accept. Payment declines predict declines in the propensity to accept new patients for both Medicare and Medicaid patients. Notably, the estimated effect for Medicaid is twice as strong as for Medicare. This indicates that changes in practice patterns do not merely affect the supply of care to patients whose payers initiated changes in reimbursement rates. Instead, the evidence suggests that increased capacity benefits those who may have otherwise had the least access to care.

Table 5 presents results for weeks worked and income. The elasticity of 0.014 for weeks worked is statistically insignificant and economically modest. The estimated income elasticity suggests that a ten percent increase in prices causes a 2.5 percent increase in income in the short-run, but recall that physician income is very poorly measured in survey data (Gottlieb et al., 2020).

A final consideration for the interpretation of these results is measurement error. We proxy for each physician's change in reimbursement rate using the specialty-level estimate described in section 4. But individual doctors are sure to be heterogeneous in how the payment change affects their average fees. This would appear as measurement error in our regressions, attenuating the estimated responses towards zero. ${ }^{24}$

The results presented in this section highlight the importance of distinguishing between revenue-generating work hours and overall labor supply. Revenue-generating patient care hours exhibit a very modestly negative wage elasticity in the years following the payment shock, which could be interpreted as slightly backward-bending labor supply. Yet the positive relation between wages and investments contradicts the notion that physicians scale back overall work in response to increased wages. This raises the question of how current policy

\footnotetext{
${ }^{24}$ The hours variables also likely contain substantial measurement error. One source of error is rounding. Appendix Figure B.7 demonstrates that the percent of responses that are a multiple of five range from 63 to 81 percent for the hours variables. We expect such measurement error to widen the confidence intervals, but otherwise be innocuous.
} 
affects long-run service supply. If investments increase the efficiency or quality of care in the long-run, then price changes will have longer-lasting effects that are missed by examining short-run responses.

\section{Conclusion}

We investigate how changes in Medicare's payment rules affect physicians' investments in their careers. We find that these investments respond positively to their returns. Over the medium run, physicians respond to an increase in reimbursement rates by increasing the time spent on investment activities. Consistent with this time investment, they become more willing to accept new patients when reimbursements increase. The increase in capacity seems to especially benefit those most likely to be residual claimants on physician capacity, such as Medicaid beneficiaries. One reason physicians may be well-positioned to respond to government payment rules is the structure of the industry. Many physicians run individual or small practices, and can choose how to allocate their time and resources. ${ }^{25}$

Our results imply that policymakers and researchers must pay close attention to physicians' investments in human capital, in the capacity of their practices, and in the length of their careers. These investments drive the health system's long-run capacity to deliver services. Because investments respond positively to payment rates, a policymaker seeking to alleviate a shortage will have long-run success by increasing payment rates rather than decreasing them. In contrast, payment reductions make sense when one thinks too much care is being provided.

These results are an important input for policymakers considering major health system reforms. A major cut in payment rates would reduce providers' incentives to increase capac-

\footnotetext{
${ }^{25}$ In recent years, physician practices have been merging and growing (Welch et al., 2013). But this trend mostly occurred after the time period we consider (Liebhaber and Grossman, 2007; Robinson, 1998), and even now one-third of physicians work in small practices (Muhlestein and Smith, 2016). Appendix Table B.1 shows the distribution of practice types for our sample.
} 
ity. This could reduce the amount of care available, and thus the system's slack capacity. This slack capacity is expensive at normal times, but could have spillover benefits for Medicaid patients and in situations when healthcare demand increases. 


\section{References}

Acemoglu, Daron and Amy Finkelstein, "Input and Technology Choices in Regulated Industries: Evidence from the Health Care Sector," Journal of Political Economy, October 2008, $116(5), 837-880$.

- and Joshua Linn, "Market Size in Innovation: Theory and Evidence from the Pharmaceutical Industry," The Quarterly Journal of Economics, August 2004, 119 (3), 1049-1090.

Alexander, Diane, "Does physician pay affect procedure choice and patient health? Evidence from Medicaid C-section use," Working Paper 2017-07, Federal Reserve Bank of Chicago 2015. Available online at https://www.chicagofed.org/publications/ working-papers/2017/wp2017-07 (accessed April 12, 2018).

Baker, Laurence C and Anne Beeson Royalty, "Medicaid policy, physician behavior, and health care for the low-income population," Journal of Human resources, 2000, pp. $480-502$.

Becker, Gary S., "Investment in Human Capital: A Theoretical Analysis," Journal of Political Economy, October 1962, 70 (5), 9-49.

Ben-Porath, Yoram, "The production of human capital and the life cycle of earnings," Journal of Political Economy, 1967, 75 (4, Part 1), 352-365.

Blahous, Charles, "The costs of a national single-payer healthcare system," Mercatus Research Paper, 2018.

Brekke, Kurt R., Tor Helge Holmås, Karin Monstad, and Odd Rune Straume, "Do Treatment Decisions Depend on Physicians' Financial Incentives?," Journal of Public Economics, November 2017, 155, 74-92.

Buchmueller, Thomas, Sarah Miller, and Marko Vujicic, "How do providers respond to changes in public health insurance coverage? Evidence from adult Medicaid dental benefits," American Economic Journal: Economic Policy, 2016, 8 (4), 70-102.

Carey, Colleen Marie, Ethan Lieber, and Sarah Miller, "Drug Firms' Payments and Physicians' Prescribing Behavior in Medicare Part D," Unpublished Working Paper, 2015.

Cassel, Christine K. and Eric S. Holmboe, "Professionalism and Accountability: The Role of Specialty Board Certification," Transactions of the American Clinical and Climatological Association, 2008, 119.

Center for Studying Health System Change, "Physician Survey Summary File: User's Guide and Codebook," 1999. Community Tracking Study Physician Survey, 1996-1997 (ICPSR 2597). Available at http://doi.org/10.3886/ICPSR02597.v3. 
Centers for Medicare and Medicaid Services, "National Health Expenditures Fact Sheet," https://www.cms.gov/Research-Statistics-Data-and-Systems/ Statistics-Trends-and-Reports/NationalHealthExpendData/NHE-Fact-Sheet 2019.

Chandra, Amitabh, David Cutler, and Zirui Song, "Who Ordered That? The Economics of Treatment Choices in Medical Care," in Thomas G. Mcguire Mark V. Pauly and Pedro P. Barros, eds., Handbook of Health Economics, Volume 2, Amsterdam: NorthHolland, 2011, chapter 6, pp. 397-432.

Chen, Alice, "Do the poor benefit from more generous Medicaid physician payments," 2014. University of Southern California, mimeo.

_ , Anthony T Lo Sasso, and Michael R Richards, "Supply-side effects from public insurance expansions: Evidence from physician labor markets," Health economics, 2018, 27 (4), 690-708.

Chown, Jillian, David Dranove, Craig Garthwaite, and Jordan Keener, "The Opportunities and Limitations of Monopsony Power in Healthcare: Evidence from the United States and Canada," Working Paper 26122, National Bureau of Economic Research 2019.

Clemens, Jeffrey and Joshua D. Gottlieb, "Do Physicians' Financial Incentives Affect Medical Treatment and Patient Health?," American Economic Review, April 2014, 104 (4), 1320-1349.

_ and _, "In the Shadow of a Giant: Medicare's Influence on Private Payment Systems," Journal of Political Economy, February 2017, 125 (1), 1-39.

- and Parker Rogers, "Demand Shocks, Procurement Policies, and the Nature of Medical Innovation: Evidence from Wartime Prosthetic Device Patents," Working Paper No. 26679, National Bureau of Economic Research 2020.

Codespote, Suzanne M., William J. London, and John D. Shatto, "Physician Volume \& Intensity Response," Memorandum to Richard S. Foster, Office of the Actuary, Health Care Financing Administration August 13 1998. Available at https://www.cms . gov/ActuarialStudies/downloads/PhysicianResponse.pdf (accessed April 12, 2018).

Congressional Research Service, "Medicare: Payments to Physicians," Technical Report, Congressional Research Service: Education and Public Welfare Division January 28 1998. Available online at http://www.law.umaryland.edu/marshall/crsreports/ crsdocuments/98-75_EPW.pdf (accessed April 12, 2018).

Cooper, Richard A., Thomas E. Getzen, Heather J. McKee, and Prakash Laud, "Economic and demographic trends signal an impending physician shortage," Health Affairs, January/February 2002, 21 (1), 140-154. 
Drolet, Brian C. and Vikram J. Tandon, "Fees for Certification and Finances of Medical Specialty Boards," JAMA, 2017, 318 (5), 477-479.

Dunn, Abe, Joshua D. Gottlieb, Adam Hale Shapiro, and Pietro Tebaldi, "The Costs of Payment Uncertainty in Healthcare Markets," 2020. University of Chicago, mimeo.

Finkelstein, Amy, "Static and dynamic effects of health policy: Evidence from the vaccine industry," The Quarterly Journal of Economics, 2004, 119 (2), 527-564.

_, "The Aggregate Effects of Health Insurance: Evidence from the Introduction of Medicare," Quarterly Journal of Economics, February 2007, 122 (1), 1-37.

Fisher, Elliott S., David E. Wennberg, Thérèse A. Stukel, Daniel J. Gottlieb, F. L. Lucas, and Étoile L. Pinder, "The Implications of Regional Variations in Medicare Spending. Part 2: Health Outcomes and Satisfaction with Care," Annals of Internal Medicine, February 18 2003, 138 (4), 288-298.

Fisher, Elliott S, John E Wennberg, Therese A Stukel, Jonathan S Skinner, Sandra M Sharp, Jean L Freeman, and Alan M Gittelsohn, "Associations among hospital capacity, utilization, and mortality of US Medicare beneficiaries, controlling for sociodemographic factors.," Health services research, 2000, 34 (6), 1351.

Foo, Patricia K., Robin S. Lee, and Kyna Fong, "Hospital and Physician Prices and Treatment Choice in Labor and Delivery," American Journal of Health Economics, Summer 2017, 3 (3), 422-453.

Garthwaite, Chen, Christopher Ody, and Amanda Stare, "Endogenous Quality Investments in the U.S. Hospital Market," NBER Working Paper Series, 2020, 27440.

Garthwaite, Craig L, "The doctor might see you now: The supply side effects of public health insurance expansions," American Economic Journal: Economic Policy, 2012, 4 (3), $190-215$.

Gottlieb, Joshua D, Adam Hale Shapiro, and Abe Dunn, "The complexity of billing and paying for physician care," Health Affairs, 2018, 37 (4), 619-626.

Gottlieb, Joshua D., Maria Polyakova, Kevin Rinz, Hugh Shiplett, and Victoria Udalova, "Who Values Human Capitalists' Human Capital? Healthcare Spending and Physician Earnings," July 2020. University of Chicago, mimeo.

Gray, Bradley M., Jonathan L. Vandergrift, Mary M. Johnston, James D. Reschovsky, Lorna A. Lynn, Eric S. Holmboe, Jeffrey S. McCullough, and Rebecca S. Lipner, "Association Between Imposition of a Maintenance of Certification Requirement and Ambulatory Care-Sensitive Hospitalizations and Health Care Costs," JAMA, 2014, 312, 2348-2357. 
Gruber, Jon, John Kim, and Dina Mayzlina, "Physician Fees and Procedure Intensity: the Case of Cesarean Delivery," Journal of Health Economics, August 1999, 18 (4), 473490.

Gruber, Jonathan and Maria Owings, "Physician Financial Incentives and Cesarean Section Delivery," RAND Journal of Economics, Spring 1996, 27 (1), 99-123.

Hadley, Jack and James D. Reschovsky, "Medicare fees and physicians. medicare service volume: Beneficiaries treated and services per beneficiary," International Journal of Health Care Finance and Economics, June 2006, 6 (2), 131-150.

Haynes, John, Jeffrey L. Jackson, Gail M. McNutt, Brian J. Hertz, Jeffrey J. Ryan, and Scott A. Pawlikowski, "Association Between Time-Unlimited vs TimeLimited Internal Board Certification and Ambulatory Patient Care Quality," JAMA, 2014, 312 (22), 2358-2363.

Heckman, James J., "A life-cycle model of earnings, learning, and consumption," Journal of Political Economy, 1976, 84 (4, Part 2), S9-S44.

Jacobson, Mireille, Tom Y. Chang, Joseph P. Newhouse, and Craig C. Earle, "Physician Agency and Competition: Evidence from a Major Change to Medicare Chemotherapy Reimbursement Policy," Working Paper No. 19247, National Bureau of Economic Research July 2013.

Johnson, Erin and Marit Rehavi, "Physicians Treating Physicians: Information and Incentives in Childbirth," American Economic Journal: Economic Policy, February 2016, $8(1), 115-141$.

Leganza, Jonathan, Stephanie Khoury, and Alex Masucci, "Health Professional Shortage Areas and Physician Location Decisions," Unpublished Working Paper, 2020.

Liebhaber, Allison and Joy M. Grossman, "Physicians Moving to Mid-Sized, SingleSpecialty Practices," Tracking Report 18, Center for Studying Health System Change August 2007. Available online at http://www .hschange.com/CONTENT/941.html (accessed April 12, 2018).

Lipner, Rebecca S., Brian J. Hess, and Robert L. Phillips, "Specialty Board Certification in the United States: Issues and Evidence," Journal of Continuing Education in the Health Professions, 2013, 33 (S1), 520-535.

_, Wayne H. Bylsma, Gerald K. Arnold, Gregory S. Fortna, John Tooker, and Christine K. Cassel, "Who is maintaining certification in internal medicine - and why? A national survey 10 years after initial certification," Annals of Internal Medicine, 2006, 144 (1), 29-36. 
McGuire, Thomas G., "Physician Agency," in Anthony J. Culyer and Joseph P. Newhouse, eds., Handbook of Health Economics, Volume 1A, Amsterdam: North-Holland, 2000, chapter 9, pp. 461-535.

- and Mark V. Pauly, "Physician response to fee changes with multiple payers," Journal of Health Economics, 1991, 10 (4), 385-410.

McKnight, Robin, "Medicare Balance Billing Restrictions: Impacts on Physicians and Beneficiaries," Journal of Health Economics, March 2007, 26 (2), 326-341.

Mincer, Jacob, "Progress in Human Capital Analysis of the Distribution of Earnings," Working Paper No. 53, National Bureau of Economic Research August 1974.

_, Schooling, Experience, and Earnings, New York: Columbia University Press for National Bureau of Economic Research, 1974.

Muhlestein, David B. and Nathan J. Smith, "Physician Consolidation: Rapid Movement From Small To Large Group Practices, 2013-15," Health Affairs, September 2016, 35 (9), 1638-1642.

Oostrom, Tamar, Liran Einav, and Amy Finkelstein, "Outpatient office wait times and quality of care for Medicaid patients," Health Affairs, 2017, 36 (5), 826-832.

Petterson, Stephen M., Winston R. Liaw, Robert L. Phillips, David L. Rabin, David S. Meyers, and Andrew W. Bazemore, "Projecting US primary care physician workforce needs: 2010-2025," The Annals of Family Medicine, 2012, 10 (6), 503-509.

Rice, Thomas H., "The Impact of Changing Medicare Reimbursement Rates on PhysicianInduced Demand," Medical Care, August 1983, 21 (8), 803-815.

_, "Physician-Induced Demand for Medical Care: New Evidence from the Medicare Program," Advances in Health Economics and Health Services Research, 1984, 5, 129-160.

- and Roberta J. Labelle, "Do Physicians Induce Demand for Medical Services?," Journal of Health Politics, Policy and Law, Fall 1989, 14 (3), 587-601.

Robinson, James C., "Consolidation of Medical Groups Into Physician Practice Management Organizations," JAMA, 1998, 279 (2), 144-149.

Schulman, Kevin A and Arnold Milstein, "The implications of "Medicare for All" for US hospitals," JAMA, 2019, 321 (17), 1661-1662.

Staiger, Douglas O., David I. Auerbach, and Peter I. Buerhaus, "Comparison of Physician Workforce Estimates and Supply Projections," JAMA, October 21 2009, 302 (15), 1674-1680. 
Welch, W. Pete, Alison Evans Cuellar, Sally C. Stearns, and Andrew B. Bindman, "Proportion Of Physicians In Large Group Practices Continued To Grow In 200911," Health Affairs, September 2013, 32 (9), 1659-1666.

Yip, Winnie C., "Physician response to Medicare fee reductions: changes in the volume of coronary artery bypass graft (CABG) surgeries in the Medicare and private sectors," Journal of Health Economics, 1998, 17 (6), 675-699. 
Figure 1: Case A: Physician who treats no group $L$ patients and treats her preferred number of group $H$ patients

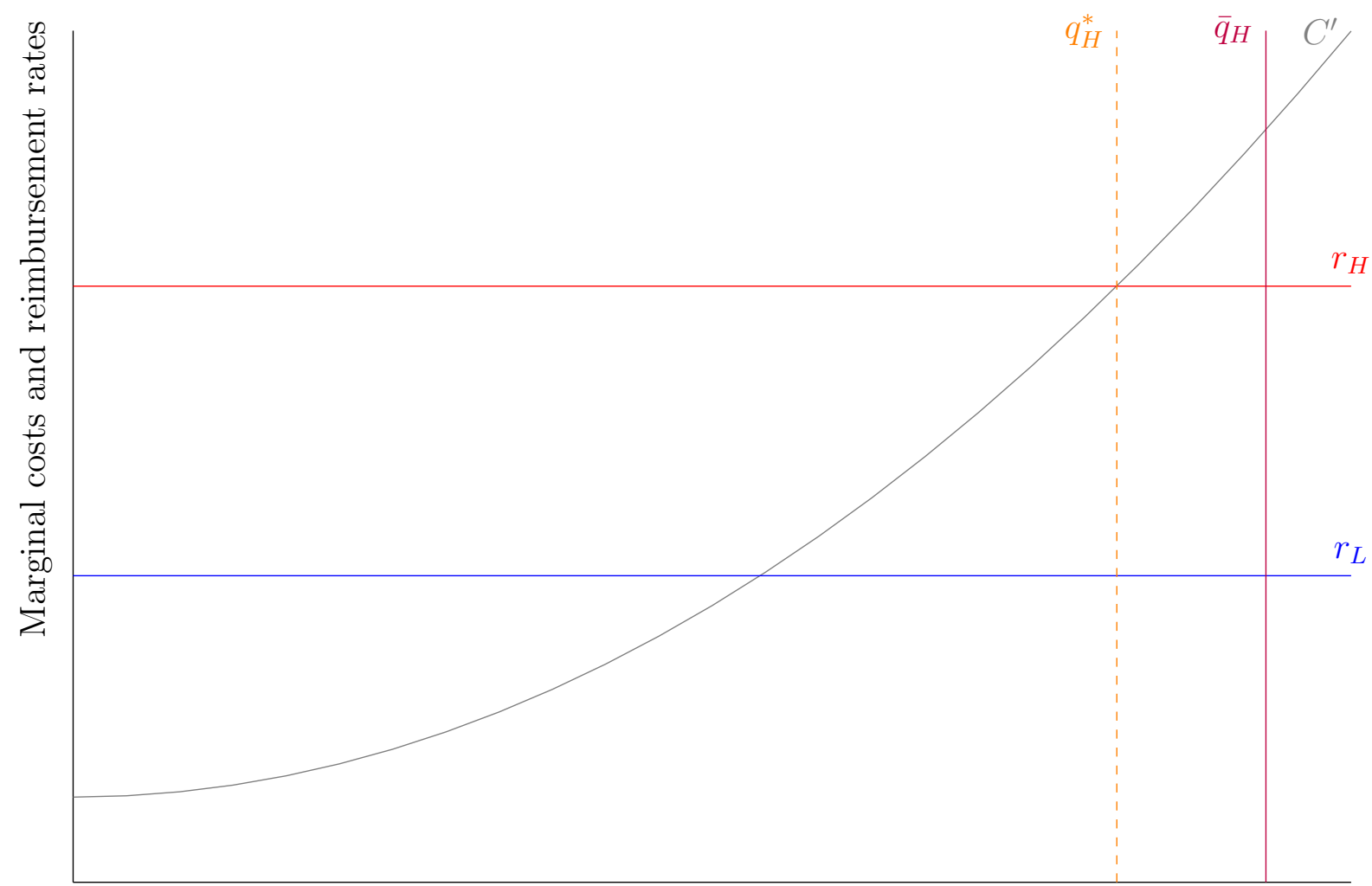

Number of patients

Note: The physician would like to treat $q_{H}^{*}$ high-paying patients, as that is the point where her marginal costs equal the reimbursement rate. There are $\bar{q}_{H}$ patients available, exceeding the ideal amount, so she treats exactly the number she would like. Since $r_{L}$ is below her marginal cost when treating $q_{H}^{*}$ high-paying patients, she does not treat any group $L$ patients. 
Figure 2: Case B: Physician who treats no group $L$ patients and is at corner solution for group $H$ patients

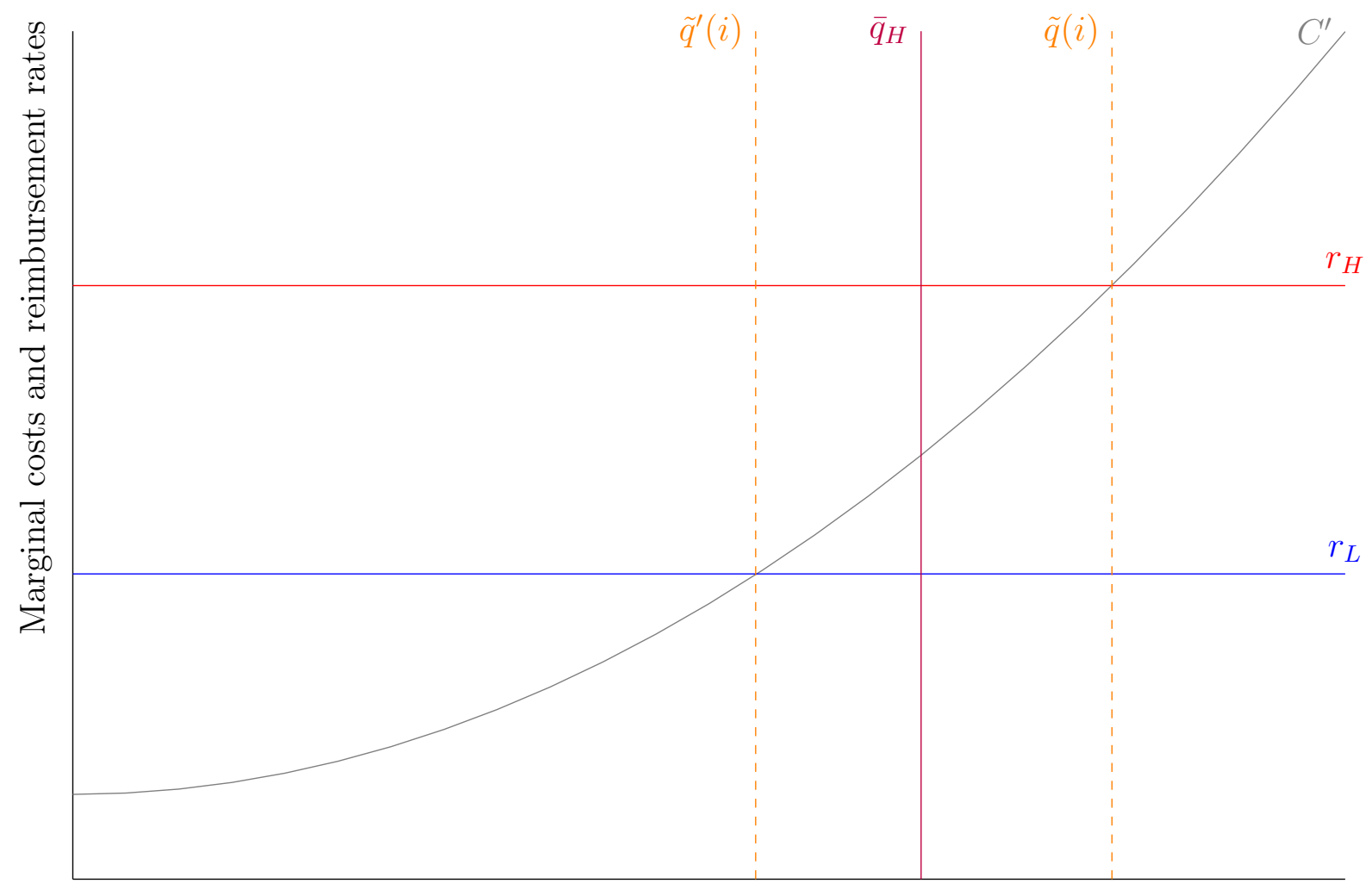

Number of patients

Note: The physician would like to treat $\tilde{q}$ high-paying patients, as that is the point where her marginal costs equal the high reimbursement rate. But only $\bar{q}_{H}$ patients are available, so that constraint is binding and she only treats $\bar{q}_{H}$ of these patients. Since $r_{L}$ is below her marginal cost when treating all available high-paying patients, she does not treat any of these lower-paying group $L$ patients. 
Figure 3: Case C: Physician who treats some group $L$ patients

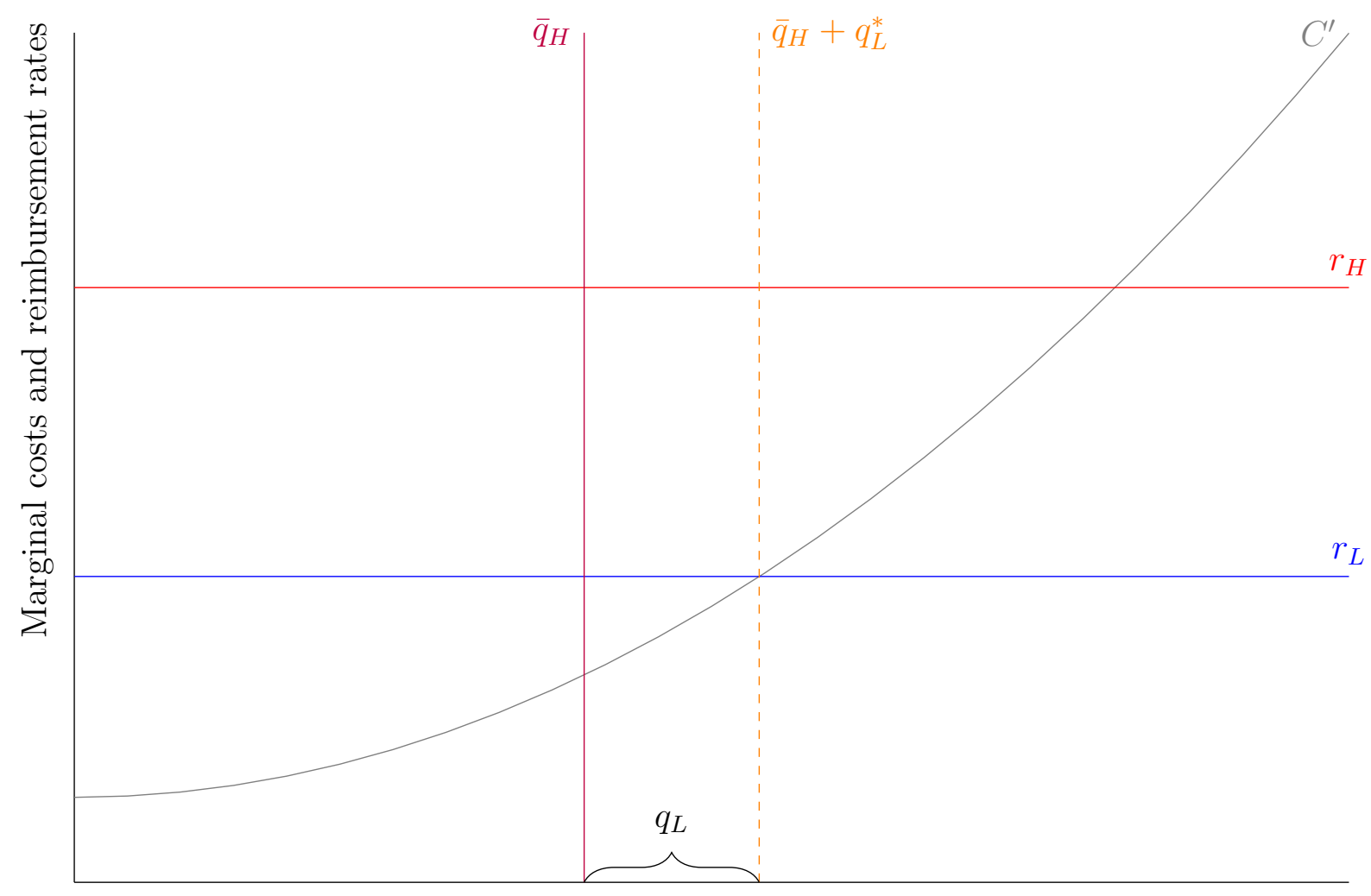

Number of patients

Note: Once again, only $\bar{q}_{H}$ high-paying patients are available, so the demand constraint is binding and she treats all of these available patients. But now $r_{L}$ is above her marginal cost when treating $\bar{q}_{H}$ high-paying patients, so she does treat some of these lower-paying patients. She does so up to the point where her marginal costs are equal to $r_{L}$, and this intersection determines $q_{L}^{*}$ and thus the total number of patients treated. 


\section{Figure 4: Physician's Investment Decision in Case C}

Panel A: Investment Payoffs and Response to Reimbursement Rate Change
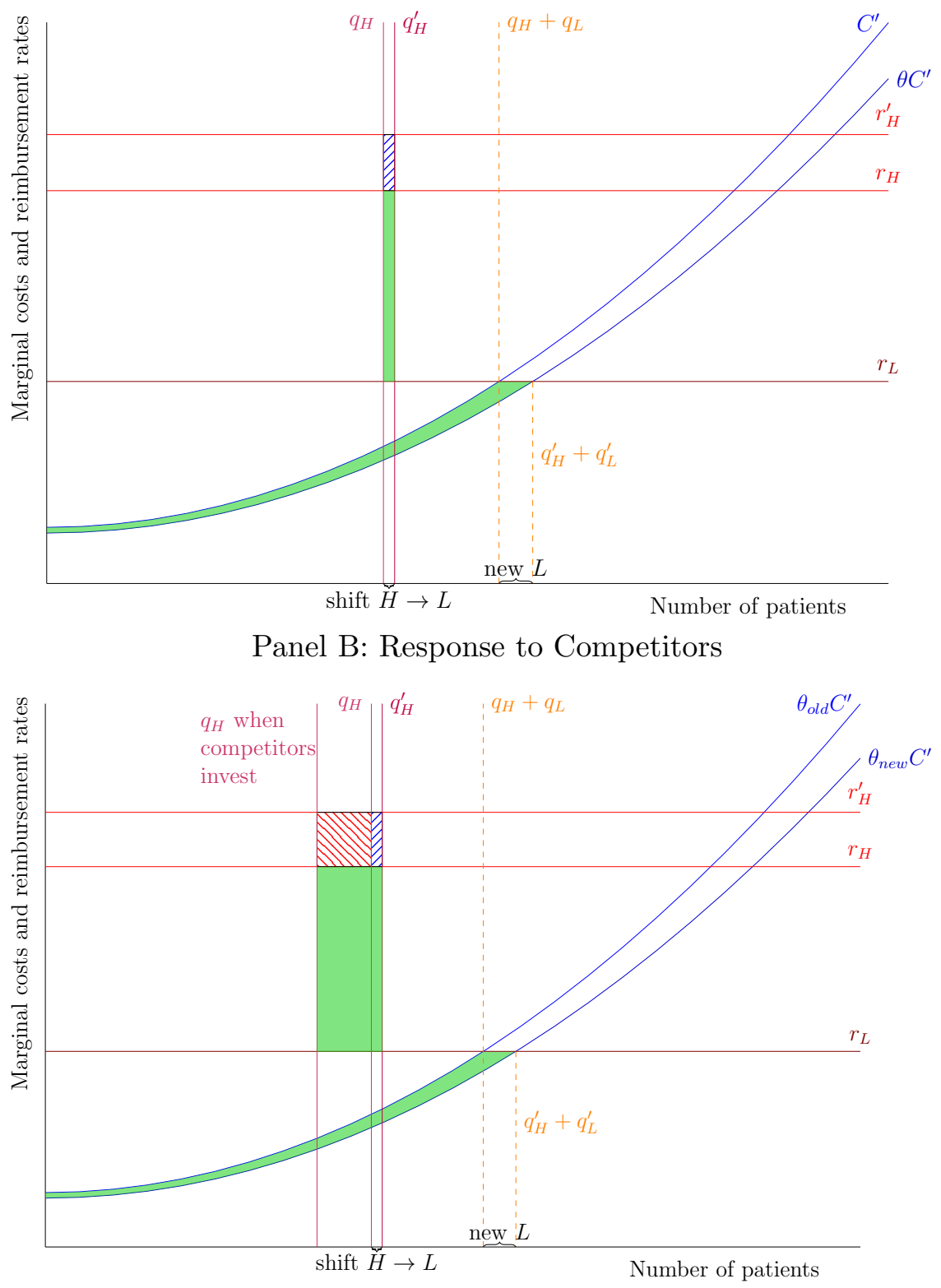

Note: Panel A illustrates the gains from a marginal increase in investment. First, investment increases the number of high-paying clients available to physician $j$, allowing her to swap low-paying for high-paying clients for a net gain of $\left(r_{H}-r_{L}\right)\left(q_{H}^{\prime}-q_{H}\right)$ (shown by the green rectangle). Second, investment reduces marginal costs (from $\theta_{\text {old }}$ to $\theta_{\text {new }}$ ) (the green area between the new and old curve). If productivity increases enough, the number of low-paying patients will increase. When $r_{H}$ increases to $r_{H}^{\prime}$, the incentive to acquire new group $\mathrm{H}$ patients rises by $r_{H}-r_{H}^{\prime}$ (the blue-dashed rectangle). Panel B shows what happens to physician $j$ when her competitors increase investment, such as in a response to an increase to $r_{H}^{\prime}$. Now $j$ will lose group $H$ market share if she doesn't also invest, as illustrated by the combination of the larger green rectangle and the red area between $r_{H}^{\prime}$ and $r_{H}$. When $j$ invests in response, her capacity for group $L$ patients. If all group $H$ patients were being treated before the rate increase, the competitive pressure to invest will increase supply of care to group $L$ patients. 
Figure 5: An increase in care demand crowds out group $L$ patients

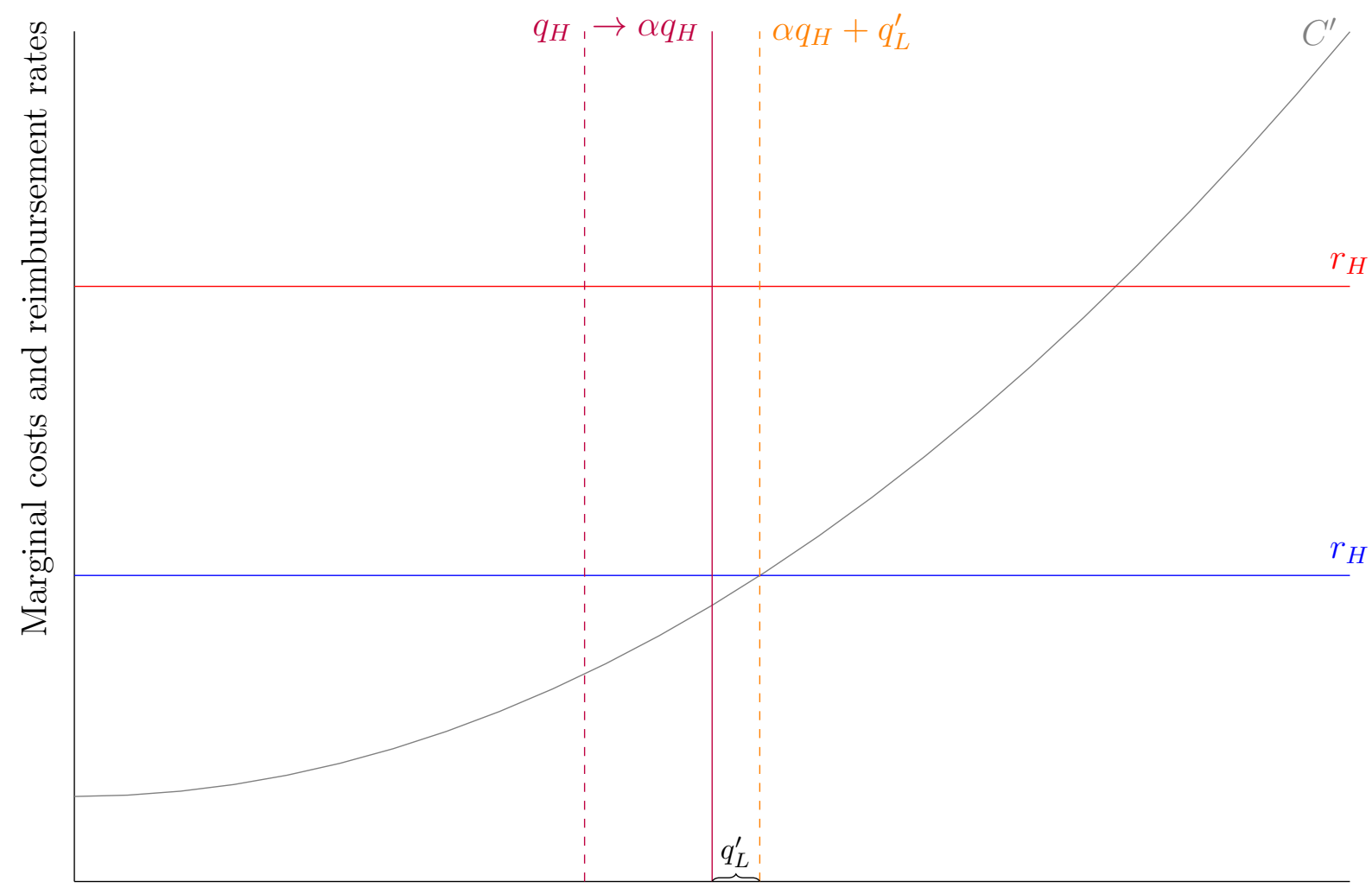

Number of patients

Note: Now $\alpha \bar{q}_{H}$ high-paying group $H$ patients are available, so the physician treats more of them and earns more. But the equilibrium condition for group $L$ is unchanged: She treats low-paying patients up to the same point, where her marginal costs are equal to $r_{L}$. The increase in demand from high-paying patients thus crowds out some of the low-paying patients, and with a larger increase could crowd out all of them. 


\section{Figure 6: Age Profile of Investment Activities and Labor Supply}

Panel A: Non-Patient Hours

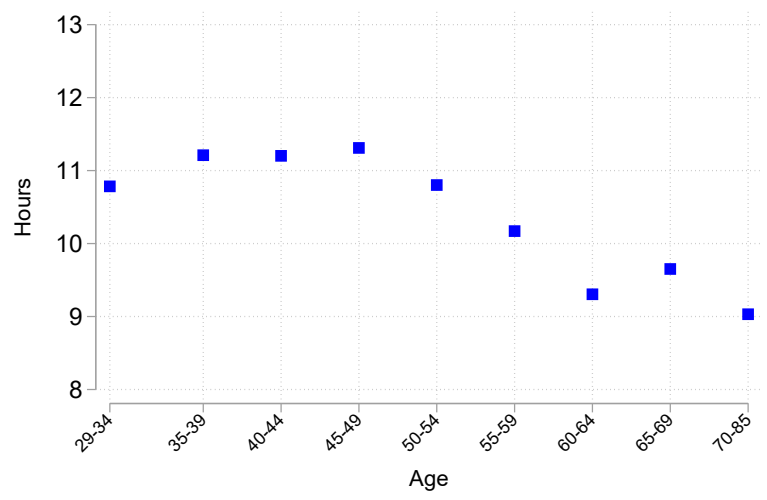

Panel C: Taking New Patients

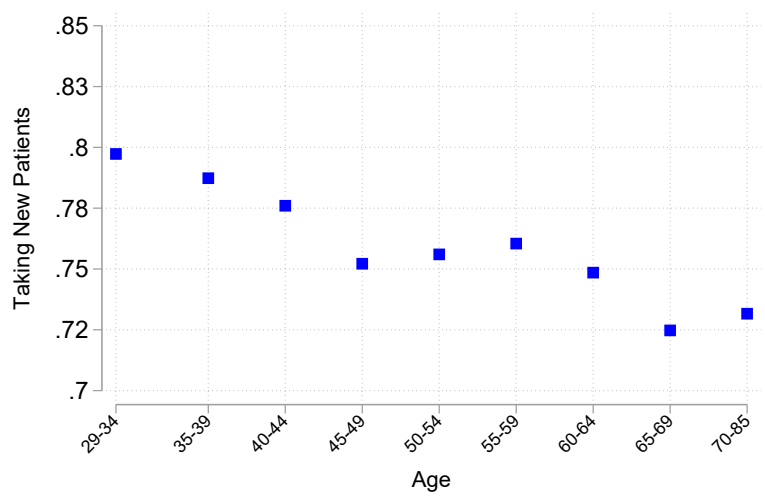

Panel E: Total Hours

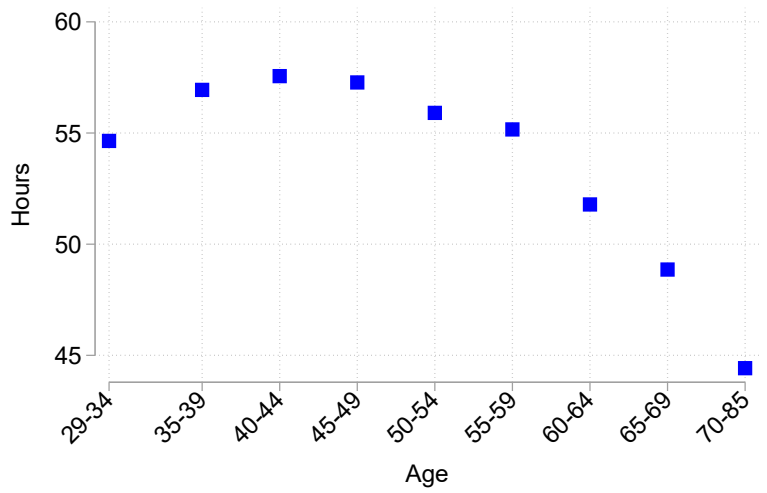

Panel B: Patient Care Hours

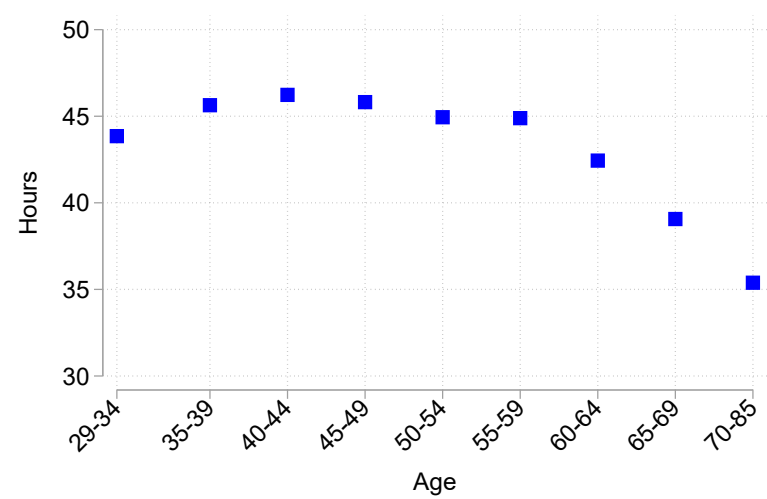

Panel D: Board Certified

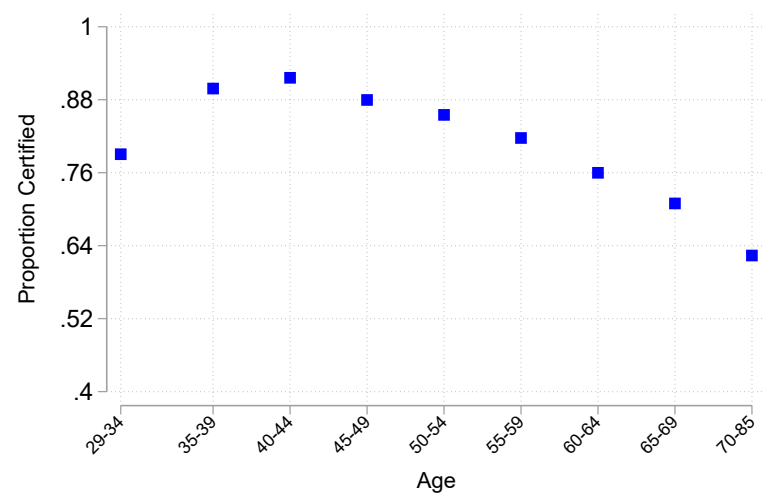

Panel F: Income

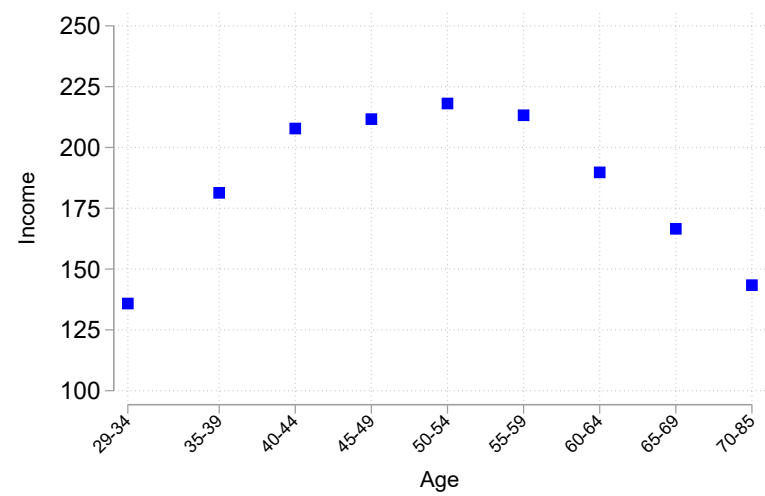

Note: This figure plots the age profile of investment activities and labor supply. Physicians are binned into five-year age bins, and the upper tail groups together those aged 70 to 85 . For each variable, the mean values within each bin are plotted. Only data from the 1996-97 wave is used. Source: Authors' calculations based on data from the Community Tracking Study, 1996/97 wave only (Center for Studying Health System Change, 1999). 
Figure 7: Non-Patient Hours Before Retirement
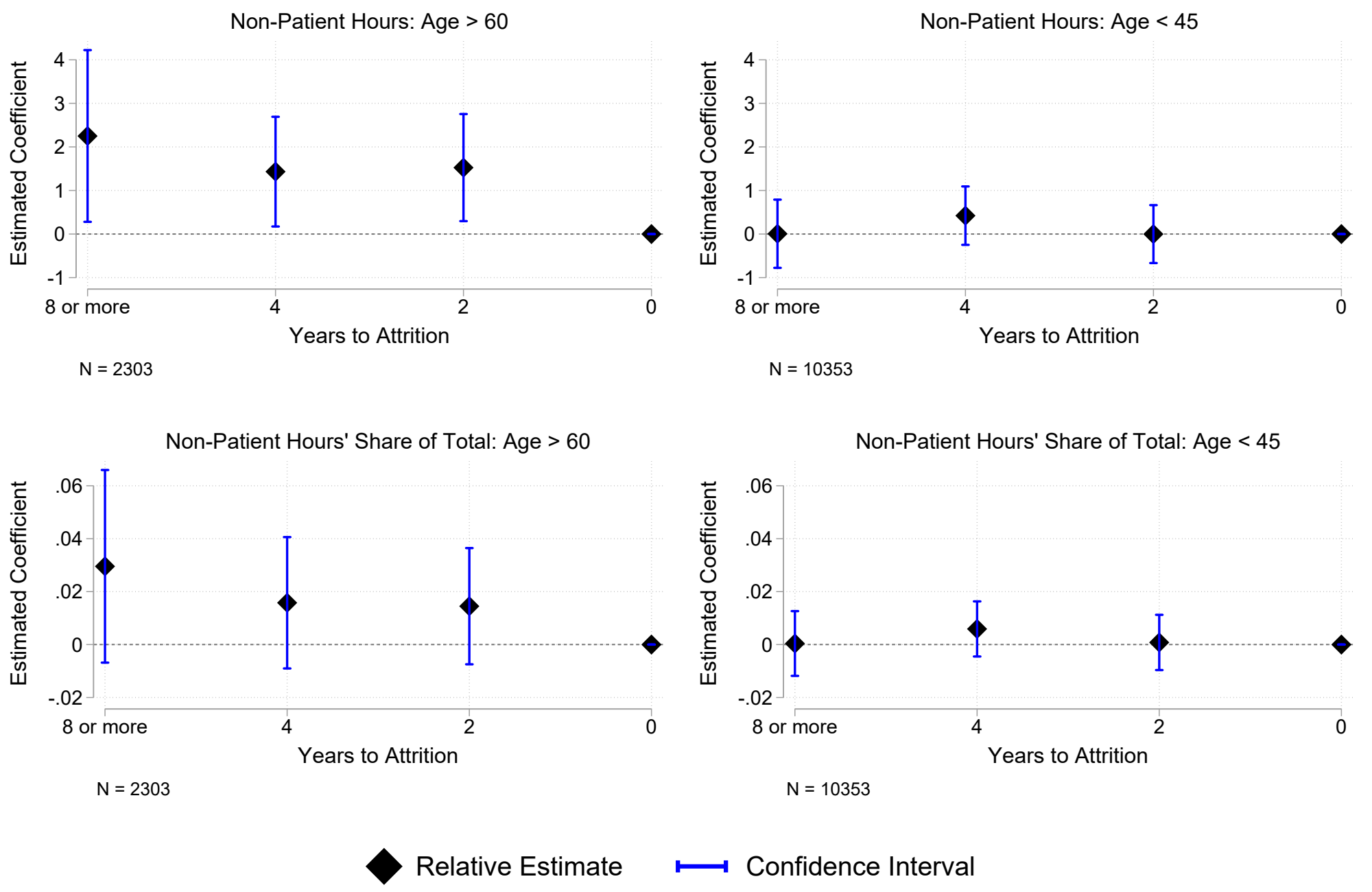

$\longmapsto$ Confidence Interval

Note: The estimated coefficients from equation (13) are shown above for non-patient hours in levels and as a share of total hours. The base group is physicians who are in their final observed period. So coefficients $\hat{\alpha}_{2}, \hat{\alpha}_{4}$, and $\hat{\alpha}_{8}$ estimate the differences in the outcome variable for physicians 2, 4, or $\geq 8$ years prior to attrition, relative to those making their final appearance in the sample. For physicians age 60 or older, weekly non-patient hours decline as they approach their final year in the Community Tracking Study panel. For young physicians, the number of years until attrition from the panel does not predict non-patient hours. Source: Authors' calculations based on data from the Community Tracking Study (Center for Studying Health System Change, 1999). 


\section{Figure 8: Dynamic Responses to Medicare Fee Change}

Panel A: Patient Care Hours

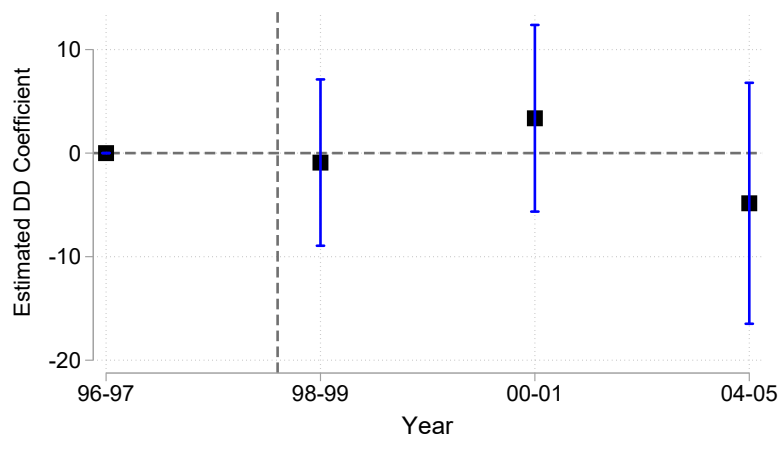

Estimated Effect of Fee Change $\longmapsto 95 \%$ Confidence Interval

Panel C: Board Certified

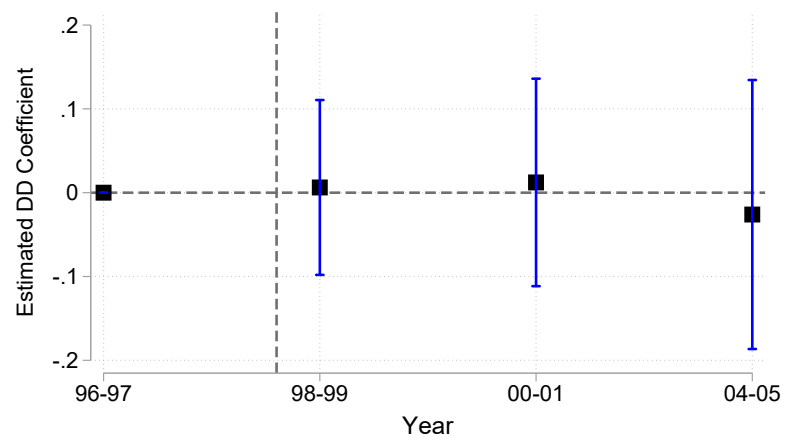

Estimated Effect of Fee Change $\longmapsto 95 \%$ Confidence Interval
Panel B: Non-Patient Hours

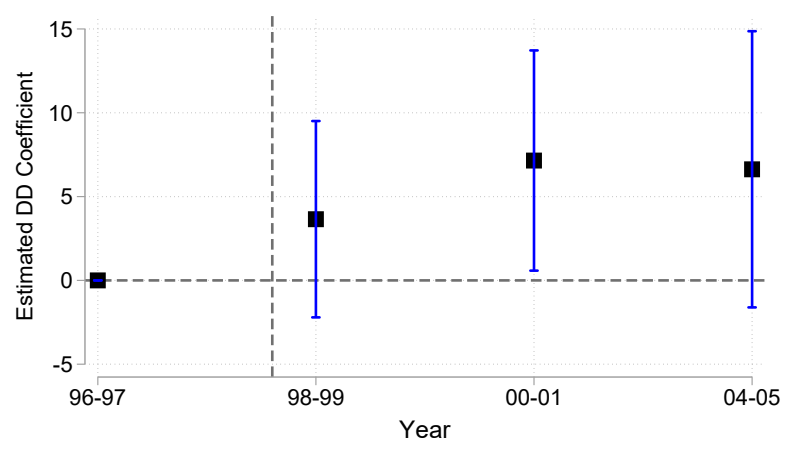

- Estimated Effect of Fee Change $\longmapsto 95 \%$ Confidence Interval

Panel D: Taking New Patients

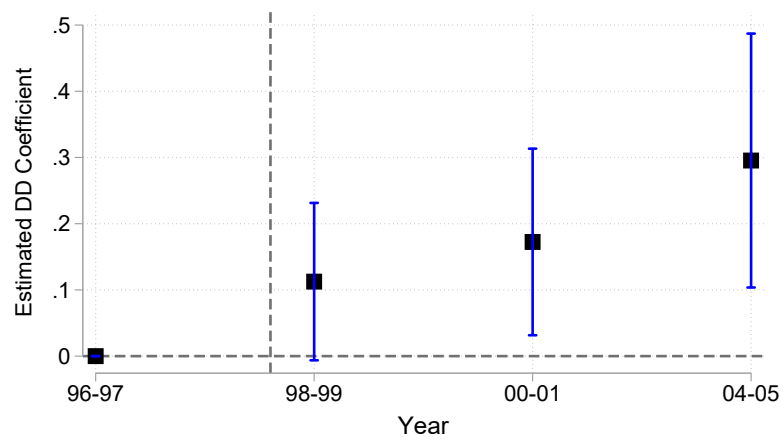

- Estimated Effect of Fee Change $\longmapsto 95 \%$ Confidence Interval

Panel E: Total Hours

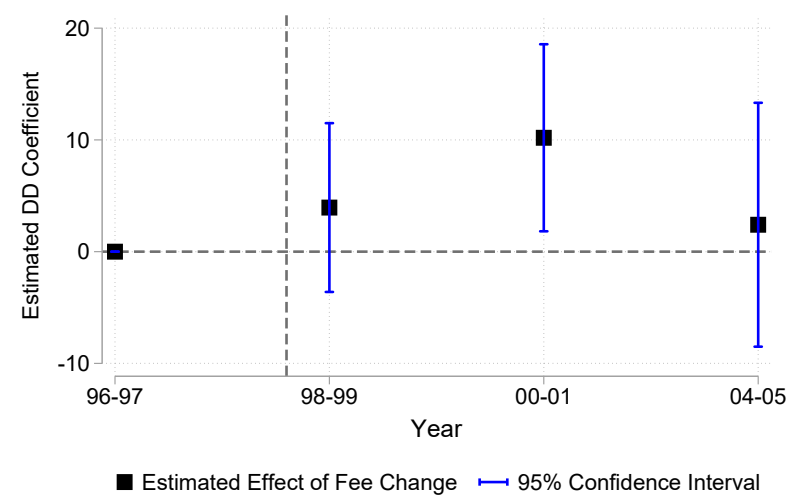

Note: This figure plots the estimates of $\hat{\beta}_{98-99}, \hat{\beta}_{00-01}$, and $\hat{\beta}_{04-05}$ from equation (14). The coefficients represent the change in the outcome variable associated with a 1 percentage point increase in the Medicare reimbursement rate for each wave after the change. Standard errors are clustered at the individual (panel unit) level and 95 percent confidence intervals are shown in blue. Source: Authors' calculations based on data from the Community Tracking Study (Center for Studying Health System Change, 1999). 


\title{
Figure 9: Changes in Patient Care and Non-Patient Hours
}

\author{
Panel A: Individual Physician Changes
}

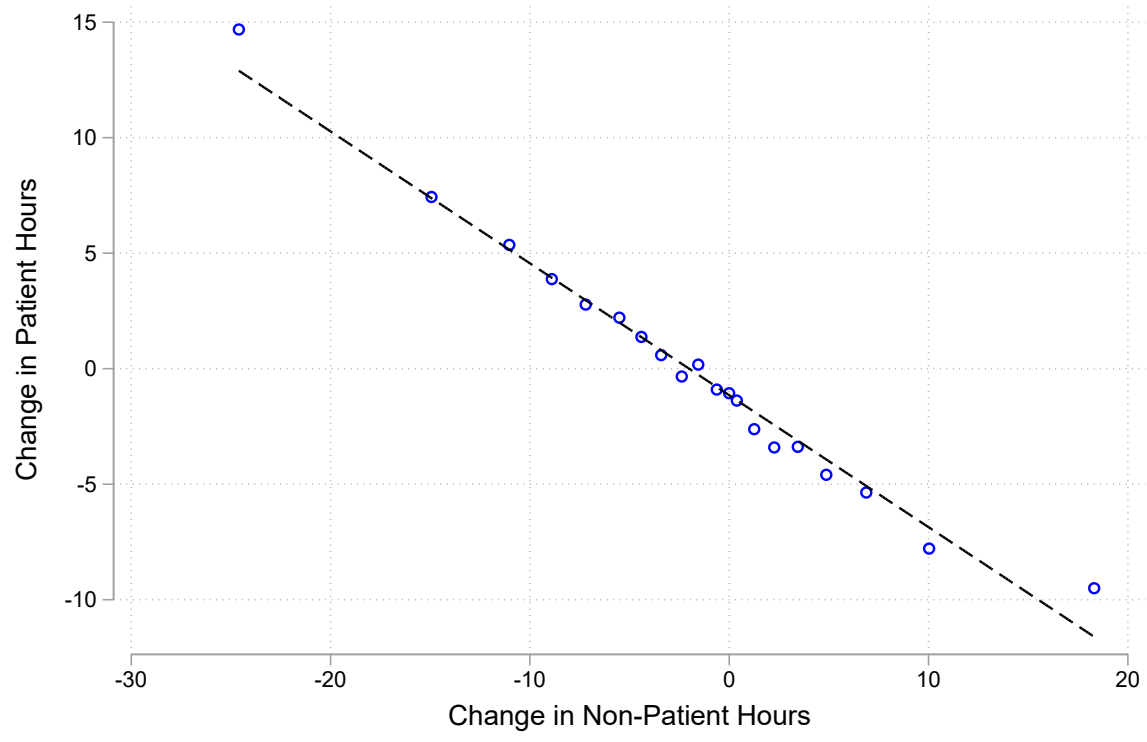

Panel B: Specialty Aggregates

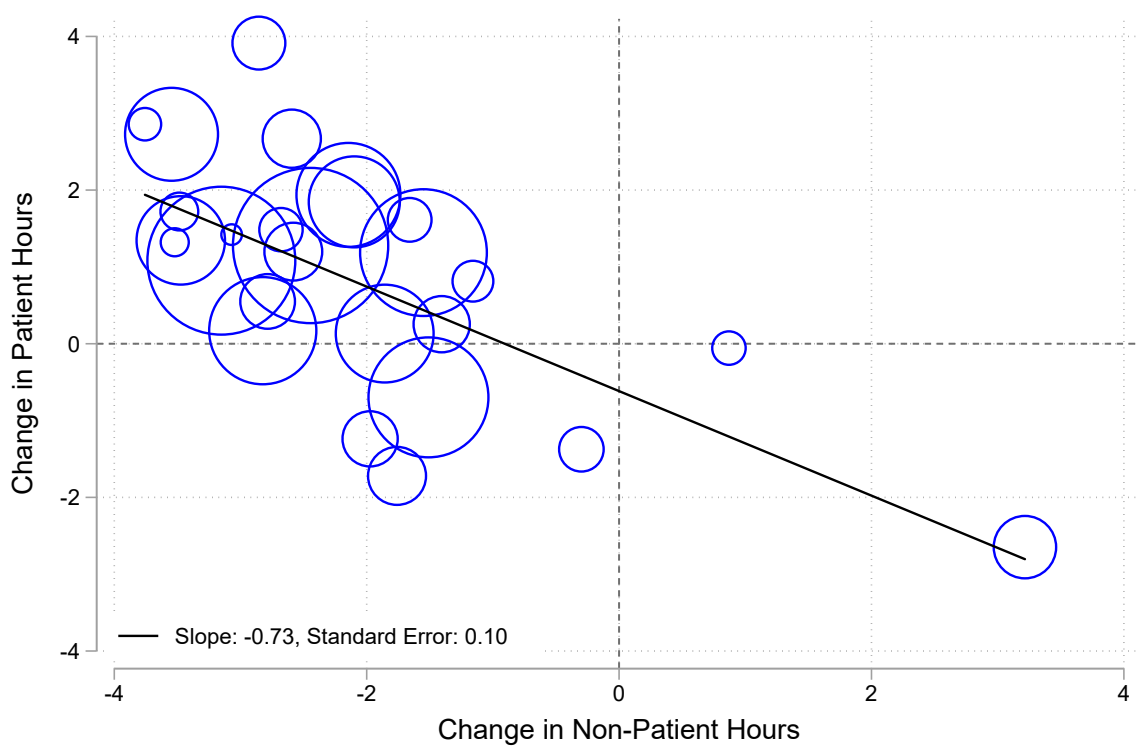

Note: In order to investigate whether physicians are trading off patient care against non-patient hours, Panel A plots the change in patient hours against that in non-patient hours by physician. We restrict the sample to physicians observed in both the 1996/97 wave at least one subsequent wave. For these physicians, we calculate the changes in patient hours and in non-patient hours between the 1996/97 response and the average of all responses in subsequent waves. We display a binned scatterplot of this relationship, by forming 20 equally sized bins grouped based on the change in non-patient hours. Panel B shows the same exercise, but where changes are calculated at the specialty level, rather than the individual level. Aggregating to the specialty level should mitigate the effects of any potential measurement error that might bias the individual-level relationship shown in Panel A. 


\section{Figure 10: Income and Weeks Worked Responses to Medicare Fee Change}

Panel A: Log Income

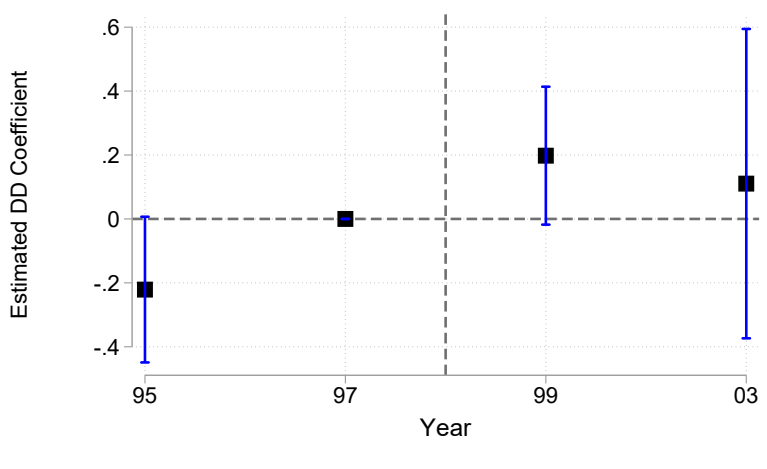

Estimated Effect of Fee Change
Panel B: Weeks Worked

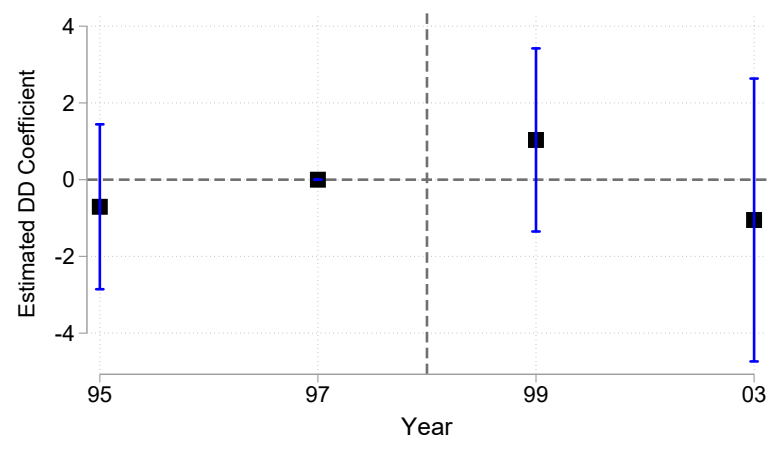

Estimated Effect of Fee Change $\longmapsto 95 \%$ Confidence Interval

Note: Income and weeks worked are reported for the years 1995, 1997, 1999, 2003, allowing only a narrow look at potential differing pre-trends. Panels A and B plot the dynamic estimates from equation (14), except the coefficients of interest are $\hat{\beta}_{95}, \hat{\beta}_{99}$, and $\hat{\beta}_{03}$. The coefficients represent the change in the outcome variable associated with a 1 percentage point increase in the Medicare reimbursement rate for each year relative to 1997. Standard errors are clustered at the individual (panel unit) level and 95 percent confidence intervals are shown in blue. Source: Authors' calculations based on data from the Community Tracking Study (Center for Studying Health System Change, 1999). 
Table 1: Predicted Medicare Fee Changes by Specialty

\begin{tabular}{lclc}
\hline Specialty & Change (\%) & Specialty & Change (\%) \\
\hline Cardiac Surgery & -9.18 & Critical Care (Intensivists) & 5.41 \\
Radiation Oncology & -8.83 & Pediatric Medicine & 5.55 \\
Thoracic Surgery & -8.08 & Preventive Medicine & 5.81 \\
Plastic/Reconstructive Surgery & -7.45 & Addiction Medicine & 5.83 \\
Colorectal Surgery (Proctology) & -7.25 & Hematology & 5.91 \\
Neurosurgery & -6.44 & Physical Medicine and Rehab. & 5.93 \\
General Surgery & -5.54 & Rheumatology & 6.10 \\
Orthopedic Surgery & -5.49 & Hematology-Oncology & 6.25 \\
Surgical Oncology & -5.09 & Medical Oncology & 6.26 \\
Dermatology & -4.97 & General Practice & 6.36 \\
Hand Surgery & -4.90 & Pulmonary Disease & 6.62 \\
Vascular Surgery & -4.85 & Emergency Medicine & 6.76 \\
Maxillofacial Surgery & -4.76 & Internal Medicine & 6.92 \\
Ophthalmology & -3.44 & Neurology & 7.11 \\
Sports Medicine & -2.87 & Family Practice & 7.23 \\
Gastroenterology & -2.77 & Intensive Cardiac Rehab. & 7.30 \\
Nephrology & -2.59 & Neuropsychiatry & 7.50 \\
Gynecological Oncology & -2.22 & Infectious Disease & 7.85 \\
Obstetrics \& Gynecology & -0.68 & Allergy Immunology & 7.97 \\
Otolaryngology & 0.11 & Geriatric Medicine & 8.00 \\
Urology & 0.61 & Psychiatry & 8.10 \\
Osteopathic Manipulative Med. & 3.17 & Endocrinology & 8.11 \\
Cardiology & 4.95 & Psychologist, Clinical & 8.37 \\
\hline Note This table shows the prat &
\end{tabular}

Note: This table shows the predicted Medicare fee changes by specialty. We estimate these using data provided in the Physician/Supplier Procedure Summary (PSPS) file released by the Centers for Medicare and Medicaid Services. This file reports state-level aggregate data on Medicare's purchases of care from physicians and other professional suppliers at the service line level. For each state and individual medical service, the file reports how many services Medicare purchased and how much it spent. To estimate the overall percent change in payments by specialty, we look at each specialty's composition of services as of 1997. We take a weighted average of the Conversion Factor change, where each specialty's weight depends on the share of Medicare spending that comes from surgical procedures. 
Table 2: Changes in Hours and Capacity

\begin{tabular}{lccccc}
\hline & $\begin{array}{c}\text { Total } \\
\text { Hours }\end{array}$ & $\begin{array}{c}\text { Patient } \\
\text { Hours }\end{array}$ & $\begin{array}{c}\text { Non-Patient } \\
\text { Hours }\end{array}$ & $\begin{array}{c}\text { Taking } \\
\text { New Patients }\end{array}$ & Certified \\
\hline \hline Price Change $\times$ Post & 5.54 & -0.38 & $5.25^{*}$ & $0.16^{* *}$ & 0.00 \\
& {$[-1.43,12.52]$} & {$[-7.86,7.10]$} & {$[-0.16,10.66]$} & {$[0.05,0.27]$} & {$[-0.10,0.10]$} \\
\hline $\mathrm{N}$ & 31,760 & 31,760 & 31,760 & 31,760 & 31,756 \\
Outcome Mean $(1996 / 97)$ & 54.48 & 43.87 & 10.52 & 0.74 & 0.83 \\
Elasticity & 0.102 & -0.009 & 0.499 & 0.218 & 0.002 \\
\hline
\end{tabular}

Note: Estimates from equation (15) are shown for Total Work Hours, Patient Care Hours, Non-Patient Hours, Board Certification, and Willingness to Take New Patients. The coefficients displayed are from the interaction between a Post-1997 indicator and the predicted percentage change in Medicare payments by specialty, scaled to be between zero and one. The coefficients thus represent the change in the outcome variable associated with a 100 percent increase in the Medicare reimbursement rate. The implied elasticities are obtained by dividing the coefficient by the mean of the outcome variable in the 1996/97 wave. Standard errors are clustered at the individual level. Stars indicate coefficients statistically distinguishable from zero, with **: $p<0.05, *: p<0.10$. Source: Authors' calculations based on data from the Community Tracking Study (Center for Studying Health System Change, 1999).

Table 3: Comparison of Care Supply Across Insurer Type

\begin{tabular}{lccccc}
\hline & Medicaid & Medicare & Private & All & N \\
CTS (1996 to 2005) & & & & & \\
\hline Accepting New Patients & 0.78 & 0.88 & 0.95 & 0.97 & 43866 \\
\hline NAMCS (2003 to 2006) & & & & & \\
\hline Accepting New Patients & 0.71 & 0.84 & 0.94 & 0.96 & 4502 \\
Fraction of Visits & 0.12 & 0.24 & 0.64 & 1.00 & 96794 \\
Mean Visit Length & 17.58 & 19.01 & 18.98 & 18.81 & 96794 \\
Mean Visit Length Adjusted & 16.81 & 18.83 & 19.20 & 18.82 & 96794 \\
\hline
\end{tabular}

Note: This table plots measures of patient care supply for patients with different insurance types. The first row shows the fraction of physician in the Community Tracking Study that are willing to take at least some patients. The next four rows report results from the National Ambulatory Medical Care Survey (NAMCS) waves from 2003 to 2006. The second row shows the average fraction of physicians willing to take at least some patients. NAMCS during this period was not designed as physician-level survey; the average willingness to take-new patients is the raw average across all visit observations. The third row shows the fraction of visits under each insurer type. The fourth row contains the average length of a visit in minutes. The final row contains the same after controlling for diagnosis codes in order to account for differences in health across insurer types. The final column provides the number of physician-year pairs (for willingness to accept new patients) or the number of visits (for visit statistics) underlying each average. Source: Authors' calculations based data from the Community Tracking Study (Center for Studying Health System Change, 1999) and National Ambulatory Care Survey. 
Table 4: Willingness to Take New Patients by Patient Type

\begin{tabular}{lcccc}
\hline & New Patients & New Medicare & New Private & New Medicaid \\
\hline Price Change $\times$ Post & $0.161^{* *}$ & $0.141^{*}$ & 0.067 & $0.275^{* *}$ \\
& $(0.057)$ & $(0.072)$ & $(0.075)$ & $(0.087)$ \\
\hline N & 31,760 & 31,760 & 31,760 & 31,760 \\
Mean of Dep. Var. (1996/97) & 0.74 & 0.77 & 0.83 & 0.62 \\
Implied Elasticity & 0.22 & 0.18 & 0.08 & 0.44 \\
\hline
\end{tabular}

Note: Estimates from the baseline pooled difference-in-difference are shown for willingness to take new patients by patient type: Private, Medicare, and Medicaid. The coefficients displayed are from the interaction between a Post-1997 indicator and the predicted percentage change in Medicare payments by specialty. The predicted change is scaled between zero and one. The coefficients represent the change in the outcome variable associated with a 100 percent increase in the Medicare rate. The implied elasticities are obtained by dividing the coefficient by the mean of the outcome variable in the 1996/97 wave. Standard errors are clustered at the individual level. Stars indicate coefficients statistically distinguishable from zero, with $* *$ : $p<0.05, *: p<0.10$. Source: Authors' calculations based on data from the Community Tracking Study (Center for Studying Health System Change, 1999).

Table 5: Changes in Annual Income and Weeks Worked

\begin{tabular}{lcc}
\hline & Log Income & Weeks Worked \\
\hline Price Change $\times$ Post & $0.25^{*}$ & 0.66 \\
& {$[0.01,0.50]$} & {$[-1.42,2.74]$} \\
\hline $\mathrm{N}$ & 30,298 & 30,235 \\
Outcome Mean $(1996 / 97)$ & 5.11 & 47.59 \\
Elasticity & 0.251 & 0.014 \\
\hline
\end{tabular}

Note: Estimates from the baseline pooled difference-in-difference are shown for log income and annual weeks worked. The coefficients displayed are from the interaction between a Post-1997 indicator and the predicted percentage change in Medicare payments by specialty. Income and weeks worked are reported for the years 1995, 1997, 1999, 2003, so the Post-1997 indicator captures two survey waves. Respondents that had been practicing for fewer than 2 years at the time of survey are excluded. The predicted change is scaled between zero and one. The coefficients represent the change in the outcome variable associated with a 100 percent increase in the Medicare rate. The implied elasticity for log income is the coefficient itself. The implied elasticity for weeks worked is obtained by dividing the coefficient by the mean of the outcome variable in the 1996/97 wave. Standard errors are clustered at the individual level. Stars indicate coefficients statistically distinguishable from zero, with ${ }^{* *}: p<0.05, *: p<0.10$. Source: Authors' calculations based on data from the Community Tracking Study (Center for Studying Health System Change, 1999). 


\section{Appendix for Online Publication Only}

\section{A Extended Model}

In this appendix we present a model that explicitly incorporates time use, with investments that take the form of time spent on non-patient care activities. Physicians maximize utility, as opposed to just profit. We assume that utility is quasi-linear in profit, with convex disutility from time spent either investing or treating patients. We start with a single period version of such a model, where utility is described by the equations below:

$$
\begin{aligned}
U\left(\pi\left(i, q_{H}, q_{L}\right), i, q_{H}, q_{L}\right) & =\pi\left(i, q_{H}, q_{L}\right)+v\left(i+\gamma(i)\left(q_{l}+q_{h}\right)\right) \\
\pi\left(i, q_{H}, q_{L}\right) & =q_{H} r_{H}+q_{L} r_{L}-\theta(i) C\left(q_{H}+q_{L}\right),
\end{aligned}
$$

Here $v\left(i+\gamma(i)\left(q_{l}+q_{h}\right)\right)$ is the disutility of labor time. Labor time is the sum of investment time $i$ and total patient care hours $\gamma(i)\left(q_{l}+q_{h}\right)$ where $\gamma(i)$ represents the time per patient. It would be straightforward to add scalars on $q_{L}$ and $q_{H}$ to denote different time per patient across patient types. Investment improves the efficiency with which the physician processes patients, so $\gamma(i)^{\prime}<0$, and lowers the financial cost per patient, so $\theta(i)^{\prime}<0$. We assume that $v()$ is sufficiently convex to avoid corner solutions in time use. Assume that $\gamma(i)^{\prime \prime}>0$ and $\theta(i)^{\prime \prime}>0$, i.e. returns to time investment are diminishing. Dollar-valued investment has been removed, so investment only requires the physician's time. Aside from these key differences, the model remains the same as in the baseline model in section 1 of the main text.

A more complicated model would keep dollar-denominated investment. Within such a model, it would be necessary to discuss complementarity between time investment and dollar-denominated investments. This extension, however, is not relevant to our key points. 
Taking Case C, where $q_{h}=S\left(i_{j}, s_{-j}\right)$ and $\overline{q_{h}}<\tilde{q}^{\prime}$, the optimality conditions are:

$$
\begin{aligned}
& q_{H}^{*}=\overline{q_{H}}=s\left(i_{j}^{*}, i_{-j}\right) Q_{H} \\
& q^{*}=q_{H}^{*}+q_{L}^{*} \\
& \underbrace{r_{L}}_{\begin{array}{c}
\text { MR of group } L \\
\text { patients }
\end{array}}=\underbrace{\theta\left(i^{*}\right) C^{\prime}\left(q^{*}\right)+v^{\prime}\left(q^{*}, i^{*}\right) \gamma(i)}_{\text {MC of extra patient }} \text {. } \\
& v^{\prime}\left(q^{*}, i^{*}\right)=\underbrace{s^{\prime}\left(i_{j}^{*}, i_{-j}^{*}\right) Q_{H}\left[r_{H}-\theta\left(i^{*}\right) C^{\prime}\left(q^{*}\right)\right]}_{\text {Net profit of group H patients attracted by } i}- \\
& \underbrace{\theta^{\prime}\left(i^{*}\right) C\left(q^{*}\right)}_{\begin{array}{c}
\text { cost savings on } \\
\text { existing patients } \\
\left(\theta^{\prime}(i)<0\right)
\end{array}}-\underbrace{v^{\prime}\left(q^{*}, i^{*}\right)\left[\gamma^{\prime}\left(i^{*}\right) q^{*}+\gamma(i) s^{\prime}\left(i_{j}^{*}, i_{-j}^{*}\right) Q_{H}\right]}_{\text {Marginal change in patient care time cost }}
\end{aligned}
$$

There are some new terms relative to our baseline model:

1. $v^{\prime}\left(q^{*}, i^{*}\right) \gamma(i)$ is the marginal time cost of an extra patient.

2. $v^{\prime}\left(q^{*}, i^{*}\right)$ is the new implicit price of investment. In the dollar-denominated investment model, the price of investment is constant.

3. $v^{\prime}\left(q^{*}, i^{*}\right)\left[\gamma^{\prime}\left(i^{*}\right) q^{*}+\gamma(i) s^{\prime}\left(i_{j}^{*}, i_{-j}^{*}\right) Q_{H}\right]$ is the marginal change in time cost due to (a) the changing time per patient and (b) the increase in patients due to recruitment.

4. In terms of visual exposition, the marginal cost curves illustrated in the figures should be reinterpreted as $\theta(i) C^{\prime}+\gamma(i) v^{\prime}$.

Combining the two conditions shows that, at the optimum, the net time cost of investment is equal to the increased profit from swapping high for low paying patients plus the reduced cost of treating infra-marginal patients.

$$
\underbrace{v^{\prime}\left(q^{*}, i^{*}\right)}_{\text {Marginal Cost of Investment }}=\underbrace{s^{\prime}\left(i_{j}^{*}, i_{-j}^{*}\right) Q_{H}\left[r_{H}-r_{L}\right]-\theta^{\prime}\left(i^{*}\right) C\left(q^{*}\right)-v^{\prime}\left(q^{*}, i^{*}\right) \gamma^{\prime}\left(i^{*}\right) q^{*}}_{\text {Marginal Benefit of Investment }}
$$

\section{A.1 High-Level Conditions on Functional Form}

Defining $q_{L}^{*}(i)$ as the optimal choice of low paying patients conditional on an investment level, optimal investment is determined by the intersection of marginal cost $M C\left(i, q_{L}^{*}(i)\right)$ and marginal benefit $M B\left(i, q_{L}^{*}(i)\right)$. In the dollar-denominated investment model, the marginal 
cost of investment is constant. In the time investment model, $M C$ can vary with $i$. For the first-order conditions to generate a single optimal allocation, we need a single crossing point of $M C$ and $M B$ with respect to $i$. Below we outline an intuitive set of sufficient conditions for this:

1. Zero investment is never optimal: $M C(0)<M B(0)$ This rules out situations where, for instance, $\theta(i)^{\prime}=\gamma(i)^{\prime}=0$ and $s^{\prime}\left(0, i_{-j}\right) Q_{H}\left[r_{H}-r_{L}\right]<v^{\prime}\left(q_{L}^{*}(0)\right)$, i.e. investment is purely a recruitment device, and the time cost of recruitment is less than the payoff. Given the large difference between $r_{H}$ and $r_{L}$ in practice, this seems to be a reasonable assumption.

2. Marginal Cost Slopes Upwards: $\frac{d M C(i)}{d i}>0$. This requires $i+\gamma(i)\left[q_{H}^{*}+q_{L}^{*}\right]$ to be strictly increasing in investment, which means $\frac{d\left[\gamma(i) q(i)^{*}\right]}{d i}=\gamma^{\prime}(i) q^{*}+\gamma(i) \frac{\frac{\partial q^{*}}{\partial i}}{q^{*}}>-1$. That is, the reduction in time per patient $\gamma(i)$ has to be sufficiently small relative to the increase in new patients. In our reduced-form empirical analysis, this assumption appears to hold in the aggregate since total hours weakly increase in response to a rate-induced investment increase.

To express the above condition in terms of model primitives, we need an expression for $\frac{\frac{\partial q^{*}}{\partial i}}{q^{*}}$. This is derived by totally differential (A.5) with respect to $i$ and re-arranging to arrive at:

$$
\begin{aligned}
\frac{\partial q^{*}}{\partial i} & =\frac{-\left[\theta^{\prime}(i) C^{\prime}\left(q^{*}\right)+\gamma^{\prime}(i) v^{\prime}\left(q^{*}\right)+\gamma(i) v^{\prime \prime}\left(q^{*}\right)\left[1+\gamma^{\prime} q^{*}\right]\right]}{\theta(i) C^{\prime \prime}\left(q^{*}\right)+v^{\prime \prime}\left(q^{*}\right) \gamma(i)^{2}} \\
& =\frac{\text { Change in Marginal Cost of Patient Care }\left(\text { Given } q^{*}\right) \text { Due to Increase in } i}{\text { Slope of Marginal Cost of Patient Care }}
\end{aligned}
$$

3. Marginal Benefit Slopes Downwards $\frac{d M B(i)}{d i}<0$ : There are two components of marginal benefit. The first is the business stealing effect of swapping low- for highpaying patients $s^{\prime}\left(i_{j}^{*}, i_{-j}^{*}\right) Q_{H}\left[r_{H}-r_{L}\right]$. An intuitive condition for this term to be downward sloping is that there be diminishing marginal returns of time investment into recruitment $s^{\prime \prime}\left(i_{j}^{*}, i_{-j}^{*}\right)<0$.

The second term is the reduction in marginal costs on existing patients $-\theta^{\prime}\left(i^{*}\right) C\left(q^{*}\right)-$ $v^{\prime}\left(q^{*}, i^{*}\right) \gamma^{\prime}\left(i^{*}\right) q^{*}$. Similar conditions are required here, albeit more complex. Totally 
differentiating this term with respect to $i$ gives:

$$
-[\underbrace{\theta^{\prime \prime} C()}_{>0}+\underbrace{\theta^{\prime} C^{\prime}()}_{<0}+\underbrace{q^{*} v^{\prime \prime} \gamma^{\prime} \frac{\partial q *}{\partial i}}_{<0}+\underbrace{q^{*} \gamma^{\prime \prime} v^{\prime}}_{>0}+\underbrace{\frac{\partial q *}{\partial i} v^{\prime \prime} \gamma^{\prime}}_{<0}]
$$

We need the term inside the bracket to be positive. In the simpler version of the model without time use, such that only the first two terms exist, this requires that $\frac{-\theta^{\prime \prime}}{\theta^{\prime}}>\frac{C^{\prime}()}{C()}$ : the productivity returns to investment need to diminish faster than the proportional increase in marginal costs from an extra patient. With time use, similar logic holds: by requiring that the sum of the last three terms be positive, and rearranging, we need that $\frac{-\gamma^{\prime \prime}}{\gamma^{\prime}}\left[1-\frac{\frac{\partial q^{*}}{\partial i}}{q^{*}}\right]>\frac{\frac{\partial q^{*}}{\partial i}}{q^{*}} \frac{v^{\prime \prime}}{v^{\prime}}$. That is, the investment returns to time efficiency need to be sufficiently diminishing compared to the rate at which marginal dis-utility of time rises.

Examining equation (A.9), we can determine when an increase in investment causes an increase in the total number of patients. Intuitively, if investment shifts out the marginal cost curve, total patients will increase. The denominator is positive due to convexity, so the result depends on whether the numerator is positive. In the simple model, the numerator would be $-\theta^{\prime}(i) C^{\prime}\left(q^{*}\right)$ which is positive since $\theta^{\prime}(i)<0$. With time investment, this is not guaranteed. The term $\gamma(i) v^{\prime \prime}\left(q^{*}\right)\left[1+\gamma^{\prime} q^{*}\right]$ is positive when $\left[1+\gamma^{\prime} q^{*}\right]>0$ (note the relation to the sufficient condition set out above: $\left.1+\gamma^{\prime}(i) q^{*}+\gamma(i) \frac{\frac{\partial q^{*}}{\partial i}}{q^{*}}>0\right)$. If it is sufficiently positive, the numerator could be negative, which is more likely when $v$ is extremely convex at the optimal allocation.

\section{A.2 Adding a Second Period}

This section generalizes the model to two periods. Physicians invest in the first period, which affects productivity and market share in both periods. The physician now maximizes discounted lifetime utility:

$$
\begin{aligned}
U\left(\left\{\pi\left(i, q_{H}^{j}, q_{L}^{j}\right), q_{H}^{j}, q_{L}^{j}\right\}_{j=1,2}, i\right) & =\pi\left(i, q_{H}^{1}, q_{L}^{1}\right)+v\left(i+\gamma(i)\left(q_{l}^{1}+q_{h}^{1}\right)\right) \\
& +\beta\left[\pi\left(i, q_{H}^{2}, q_{L}^{2}\right)+v\left(\gamma(i)\left(q_{l}^{2}+q_{h}^{2}\right)\right)\right],
\end{aligned}
$$

where $\beta$ is her discount factor. Investment $i$ is assumed to occur only in period 1 for simplicity. With quasi-linear utility, the physician will consume everything in the first period, 
or everything in the second period, depending on whether interest rates are higher or lower than their discounting $1+r \leq \geq \frac{1}{\beta}$. Assuming $1+r=\frac{1}{\beta}$ implies that the physician is indifferent between consumption in the two periods, delivering effectively the same outcome as assuming no borrowing. We will assume this, although it does not generally matter for studying investment and care provision.

With two periods, the payoff of investment has doubled assuming no depreciation across periods of the accrued productivity. Even with depreciation, equilibrium time investment in the first-time period will be higher than the single period model.

Because there is no investment in the second period, the second period marginal cost curve $\theta(i) C^{\prime}+\gamma(i) v^{\prime}$ shifts outward because $v$ is convex in time. This implies that a higher level of investment in the first period will result in a greater quantity of care for low-paying patients in the second period, following the condition that $r_{L}=\theta(i) C^{\prime}+\gamma(i) v^{\prime}$.

How does an increase in $r_{H}$ beginning in period 1 , and applying to both periods, affect investment? As before, the marginal effect of this policy change on the payoff of investing (in Case C) comes from rectangle $\left[q_{h}^{\prime}-q_{h}\right]\left[r_{H}^{\prime}-r_{H}\right]$. With two periods, the physician earns this return twice, causing the investment response to a given reimbursement to be higher. A higher investment response implies a greater reduction in marginal costs, and therefore is more likely to increase care provision to low-paying patients. This is especially true for period 2 because the marginal cost curve is flatter when $i=0$. Nonetheless, if $\frac{\partial S}{\partial i}$ is large enough relative to the reduction in marginal costs, a reduction in low-paying patient care will still ensue. But, as in the baseline model, considering market-level responses when all physicians invest to compete in a zero-sum game to attract high-paying patients, the supply to low-paying patients will unambiguously expand in the second period.

How does the increase in $r_{H}$ affect patient care time $\gamma(i)\left[q_{H}^{1}+q_{L}^{1}\right]$ and $\gamma(i)\left[q_{H}^{2}+q_{L}^{2}\right]$ ? This largely depends on the shape of $\gamma(i)$. Even in period 2 with no investment to crowd out patient care time, an investment-driven increase in quantity might not increase patient care hours if the efficiency gain in time per patient $\left(\gamma(i)-\gamma\left(i^{\prime}\right)\right)$ is sufficiently large. 


\section{B Supplementary Results and Robustness}

\section{Appendix Figure B.1: Cross-Sectional Relationship between Certification Status and Income}

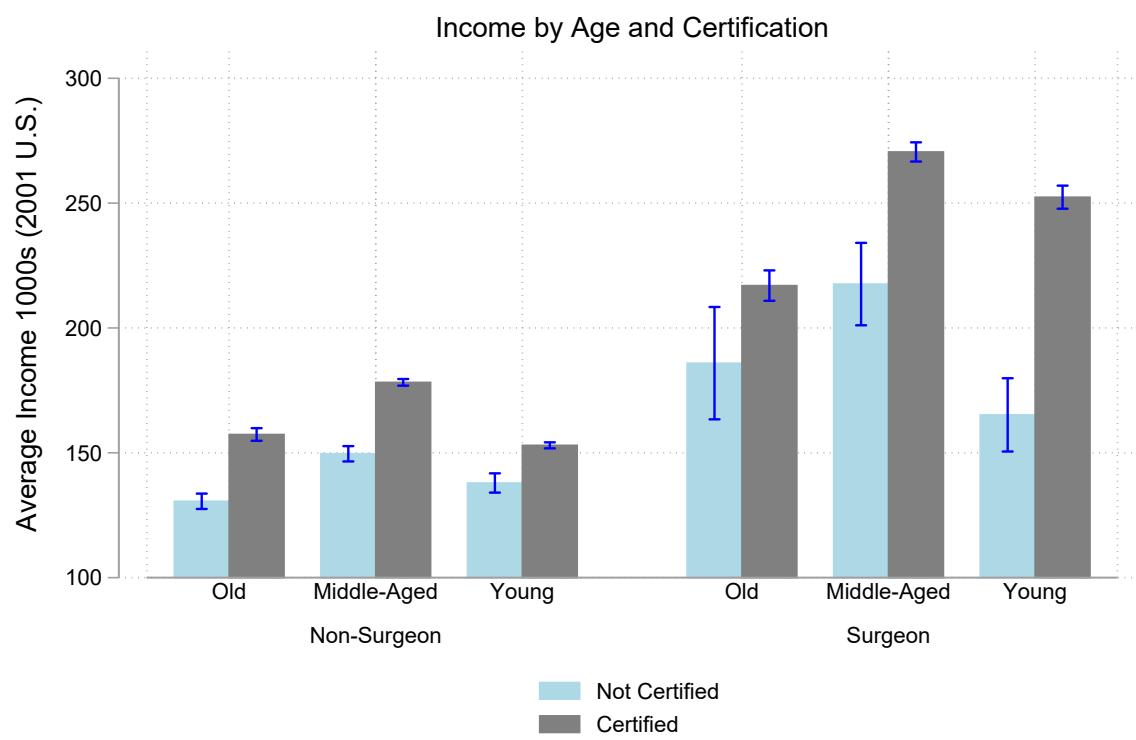

Note: This figure presents data on the incomes of physicians with and without board certification across age groups and specialties. At all age groups, and for both surgical and non-surgical specialties, certification is correlated with higher incomes. $95 \%$ confidence intervals of the means are shown. Source: Authors' calculations based on data from the Community Tracking Study, 1996/97 wave only (Center for Studying Health System Change, 1999). 


\section{Appendix Figure B.2: Attrition Rates by Age}

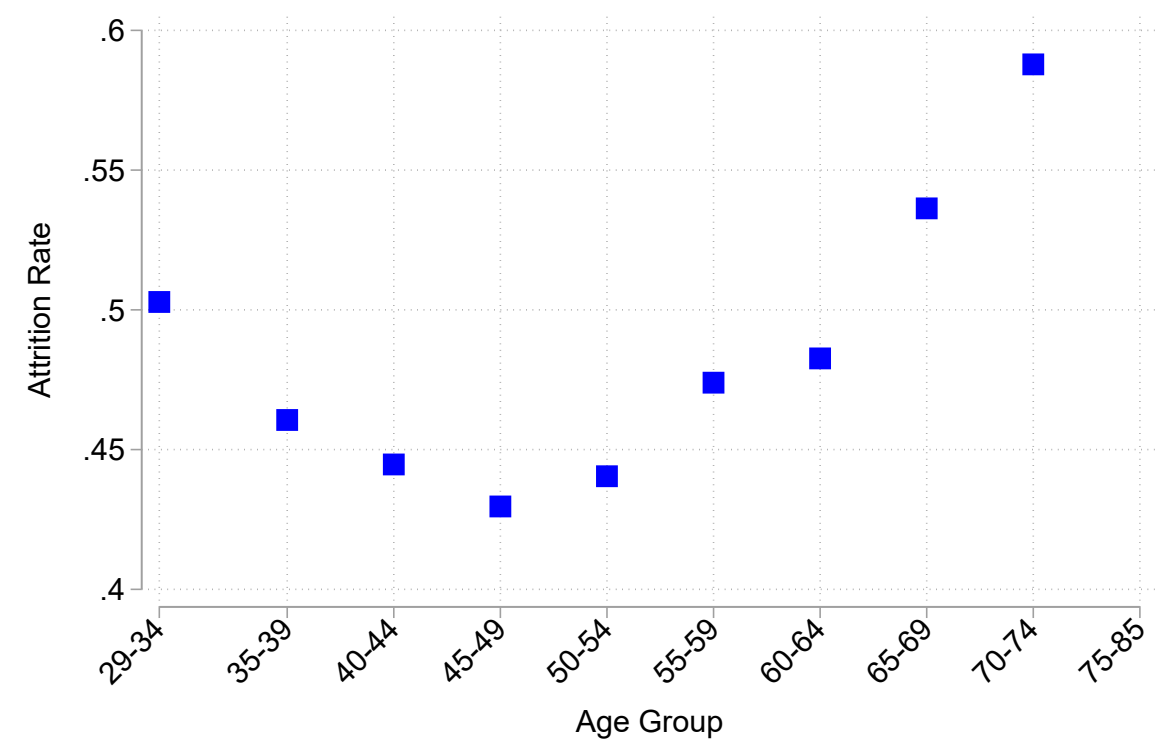

Note: This figure plots raw sample attrition rates by age group. Doctors aged 40-55 have a hazard rate of between 0.4 and 0.45 , with this rate steadily rising to 0.65 by ages $75-85$. This is suggestive of retirement driving increases in sample attrition for older physicians. Assuming that attrition among doctors aged 4549 is unrelated to retirement, and that retirement is the sole reason for increased attrition among older physicians, then we can infer that $19 \%$ of attrition among doctors aged $65-69$, and 25 percent among physicians aged $70-74$, is caused by retirement. To see this, note that the 10 percentage point differential between ages $45-49$ and $65-69$ is $19 \%$ of total attrition for the 65-69 age group. Similarly, the 15 percentage point differential between ages $45-49$ and $70-74$ is $25 \%$ of attrition among the 70-74 group. Source: Authors' calculations based on data from the Community Tracking Study (Center for Studying Health System Change, 1999). 


\section{Appendix Figure B.3: Evolution of Medicare Conversion Factors}

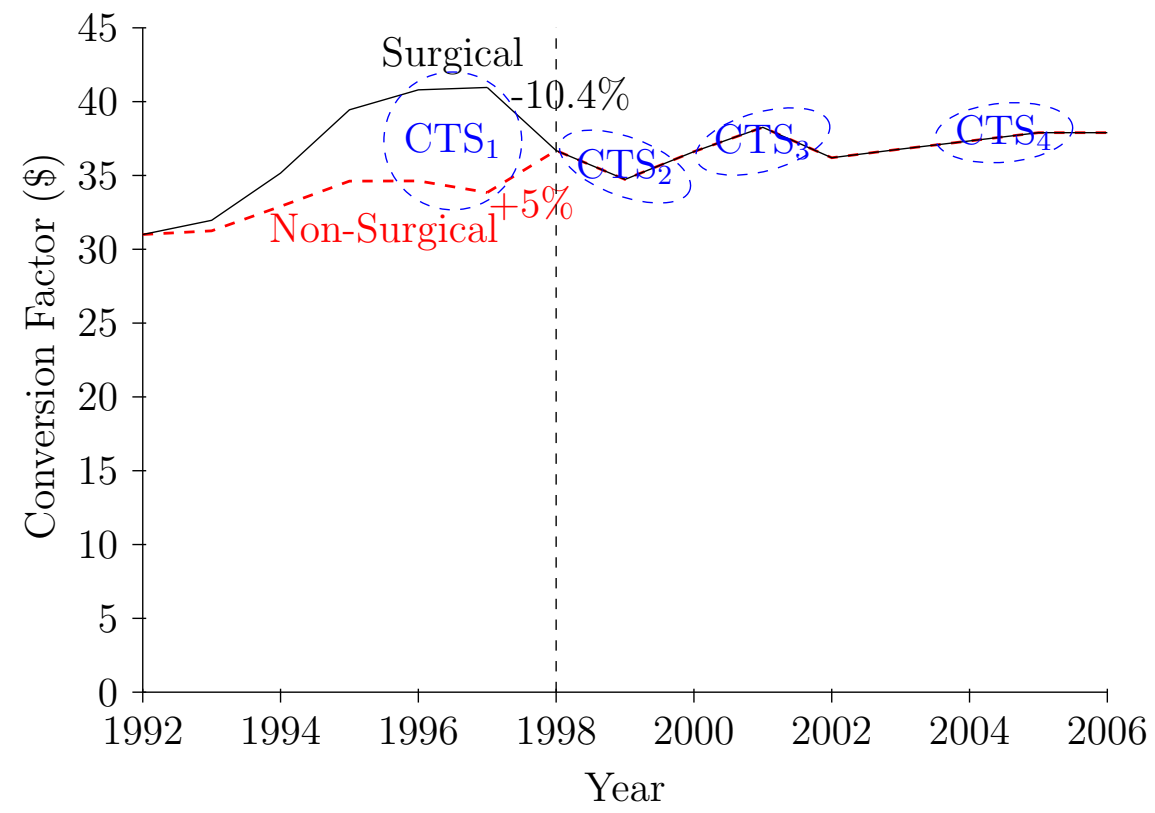

Note: This figure is adapted from Clemens and Gottlieb (2017). It plots the evolution of the Conversion Factors for surgical and non-surgical procedures in the Medicare payment schedule. The dotted circles show the survey waves of the Community Tracking Study. Original source: Federal Register, various issues

\section{Appendix Figure B.4: Weeks Worked by Age}

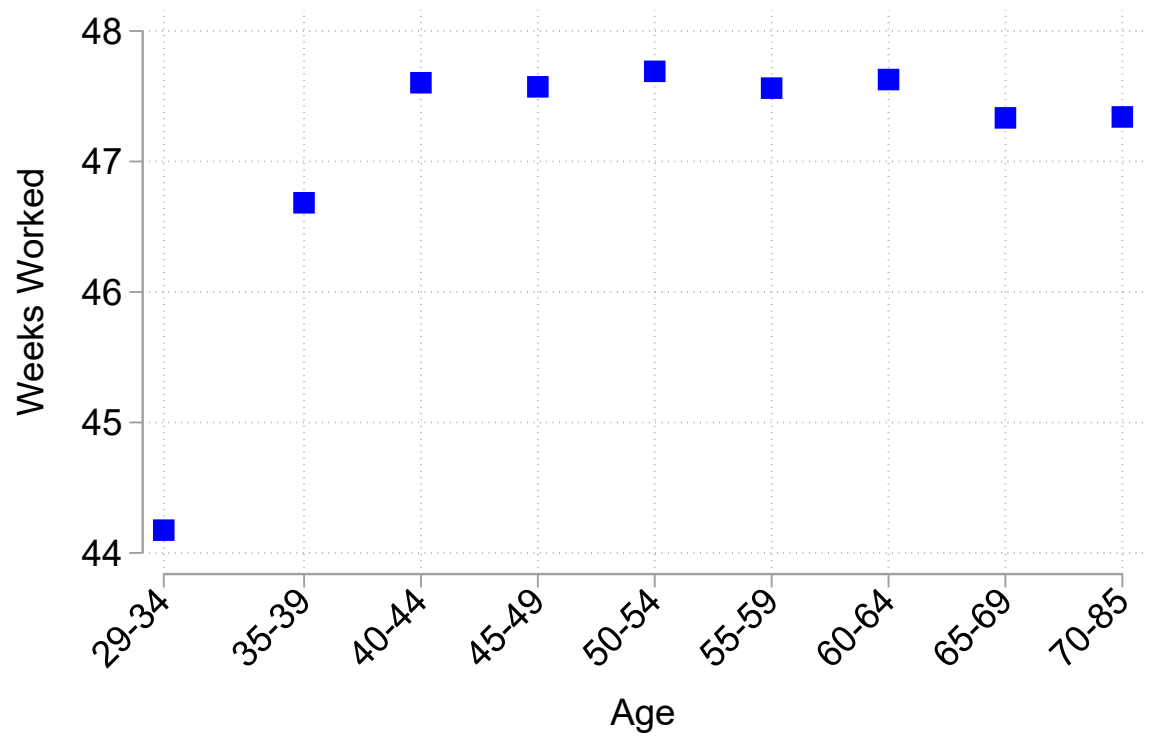

Note: 


\section{Appendix Figure B.5: Labor Supply Before Retirement}
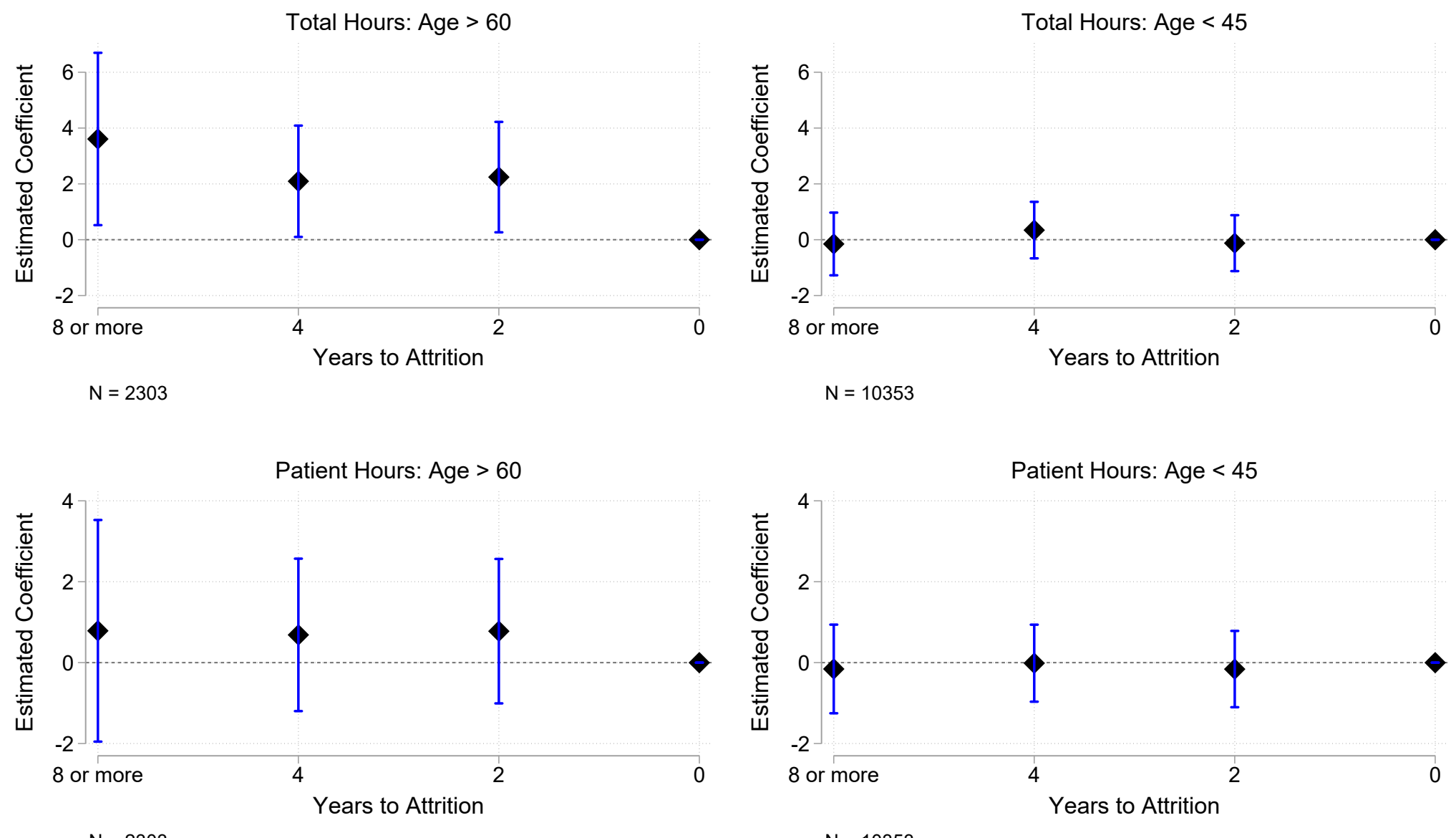

$\mathrm{N}=2303$

$N=10353$

\section{Relative Estimate $\longmapsto$ Confidence Interval}

Note: The estimated coefficients from equation (13) are shown above for total hours and patient care hours as the outcome variables. Each dot represents the difference in the outcome variable relative to the base group that attrits immediately. For physicians age 60 or older, non-patient hours decline as they approach their final year in the Community Tracking Study panel. For young physicians, the number of years until attrition from the panel does not predict non-patient hours. Source: Authors' calculations based on data from the Community Tracking Study (Center for Studying Health System Change, 1999). 


\section{Appendix Figure B.6: Other Investments Before Retirement}
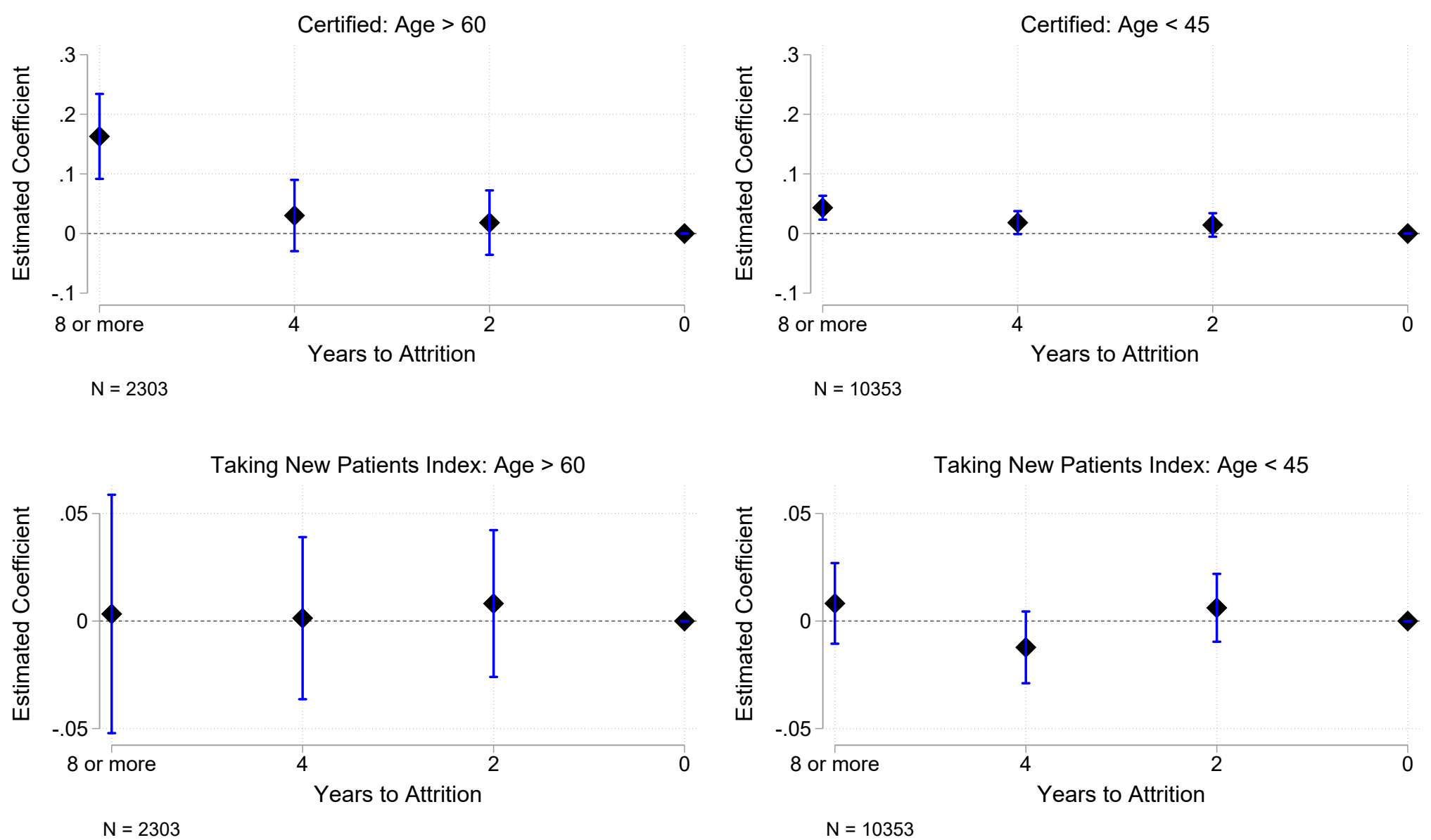

\section{$>$ Relative Estimate $\longmapsto$ Confidence Interval}

Note: The estimated coefficients from equation (13) are shown above for board certification and taking new patients as the outcome variables. Each dot represents the difference in the outcome variable relative to the base group that attrits immediately. Source: Authors' calculations based on data from the Community Tracking Study (Center for Studying Health System Change, 1999). 


\section{Appendix Figure B.7: The Magnitude of Round Number Reporting}

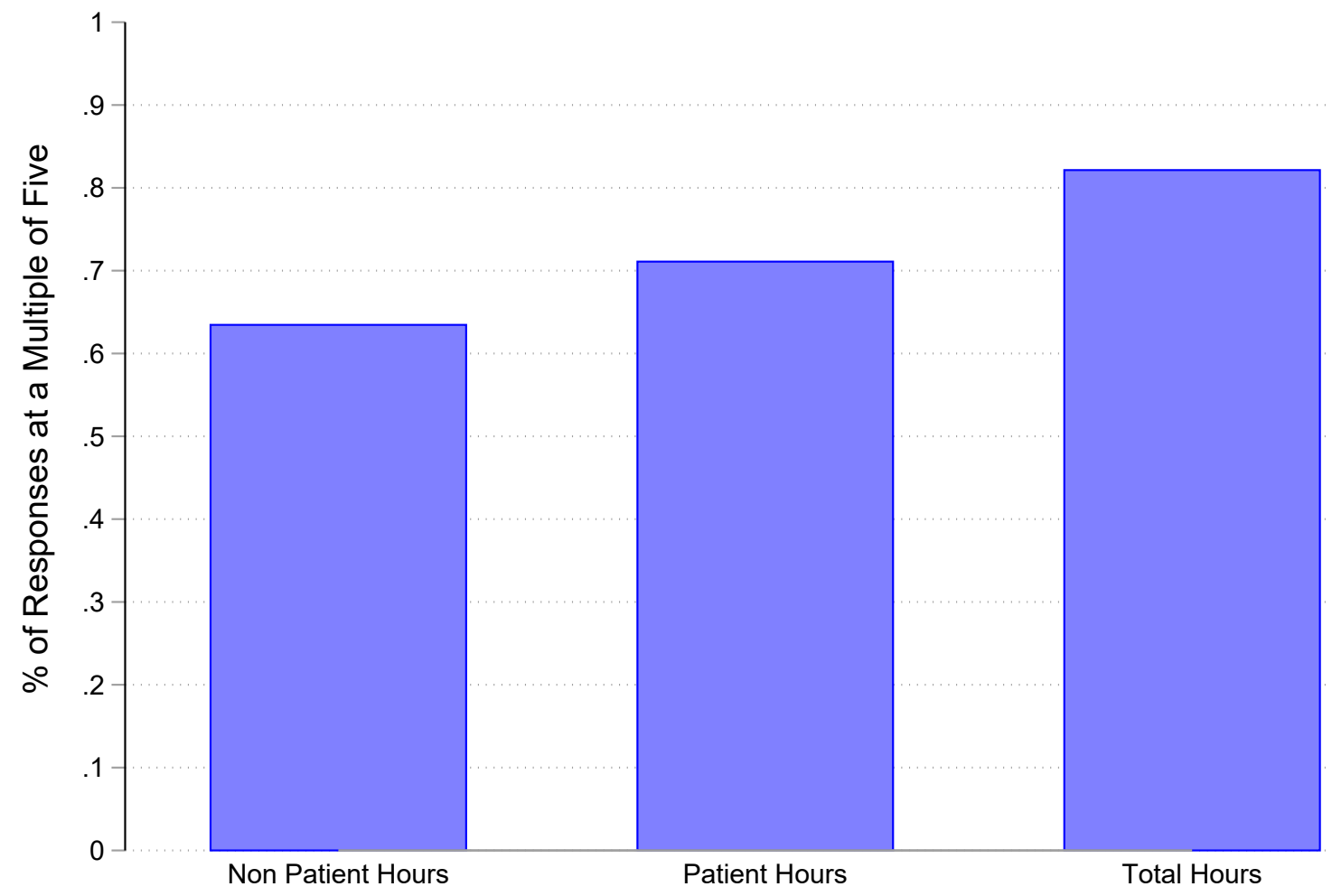

Note: This figure plots the percent of responses that are a multiple of five for each of the three hours variables. Responses with reported hours of zero are excluded from both the numerator and denominator. Source: Authors' calculations based on data from the Community Tracking Study (Center for Studying Health System Change, 1999). 


\section{Appendix Figure B.8: Cross-Sectional Age Profile of Ownership and Salary Structure}

Panel A: Own-Productivity Affects Compensation

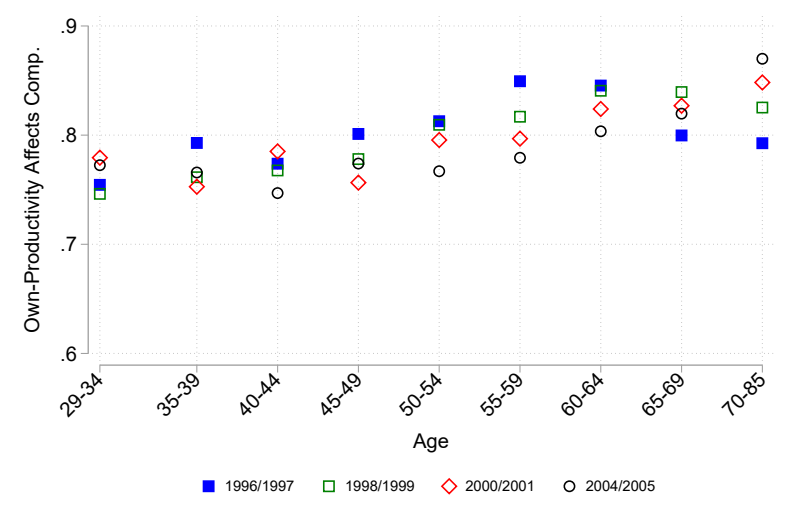

Panel B: Ownership Stake in Primary Practice

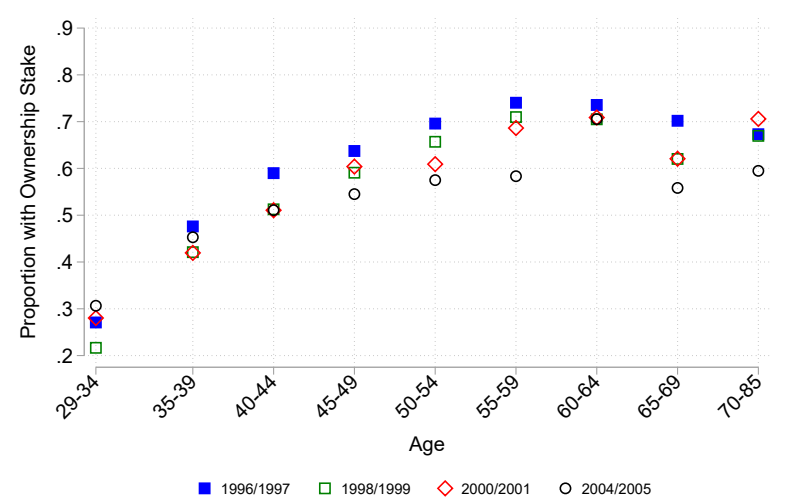

Panel C: Remunerated on a Salary Basis

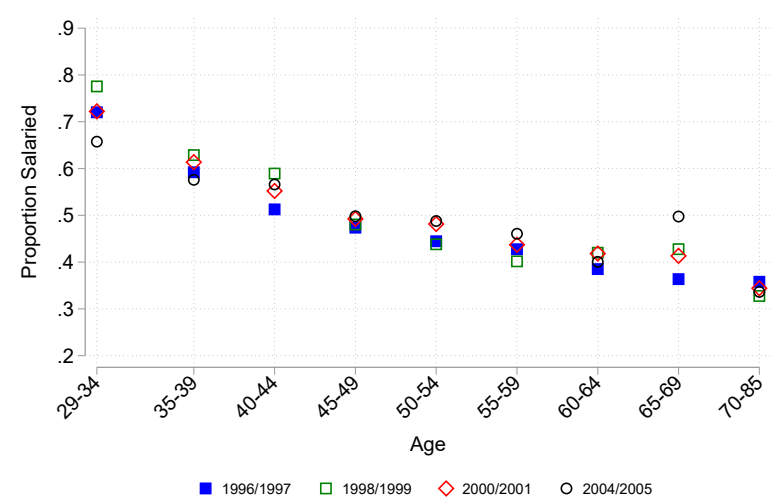

Note: Panel A plots the percent of physicians reporting that their own-productivity affects their compensation. Panel B plots the percent that are full or partial owners of their practice. Panel C shows the proportion of physicians that report being remunerated on a salary basis, each by age group. These variables may affect a physician's incentive and ability to adjust on-the-job investments in response to price changes. Given the strong correlations with age, these factors could influence the age gradient of how on-the-job investments respond to Medicare payment changes. Source: Authors' calculations based on data from the Community Tracking Study, 1997-98 wave only (Center for Studyjing Health System Change, 1999). 


\section{Appendix Figure B.9: Age Patterns by Survey Wave}

Panel A: Non-Patient Hours

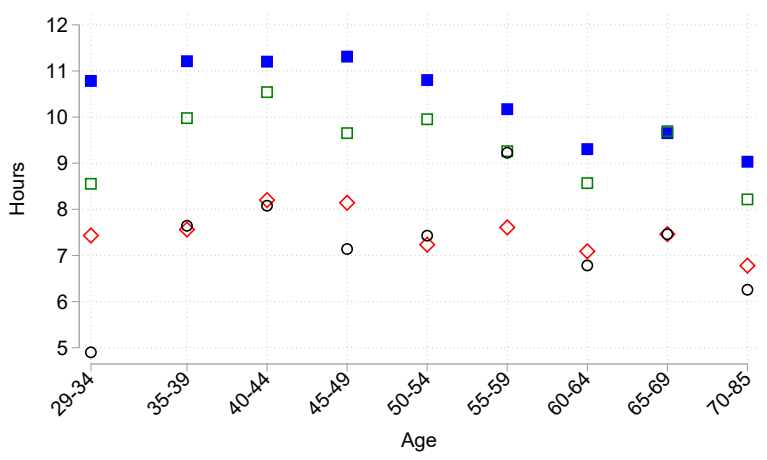

- 1996/1997 $\quad$ 口 1998/1999 $\diamond 2000 / 2001 \quad$ 2004/2005

Panel C: Board Certified

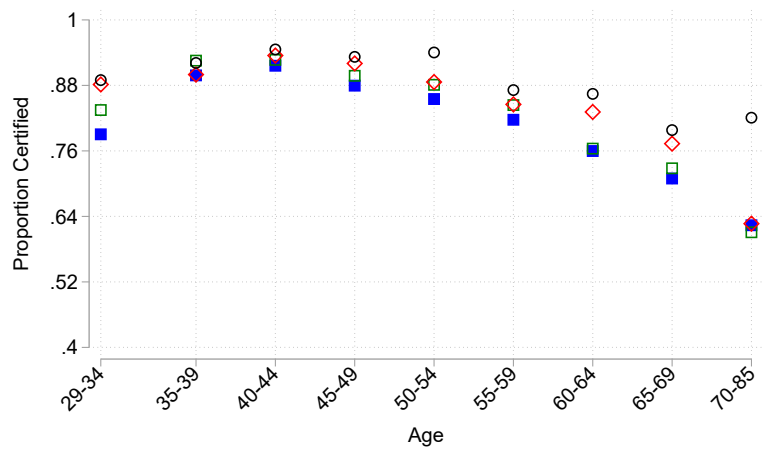

— 1996/1997 $\square$ 1998/1999 $\diamond 2000 / 2001 \quad$ 2004/2005

Panel E: Total Hours

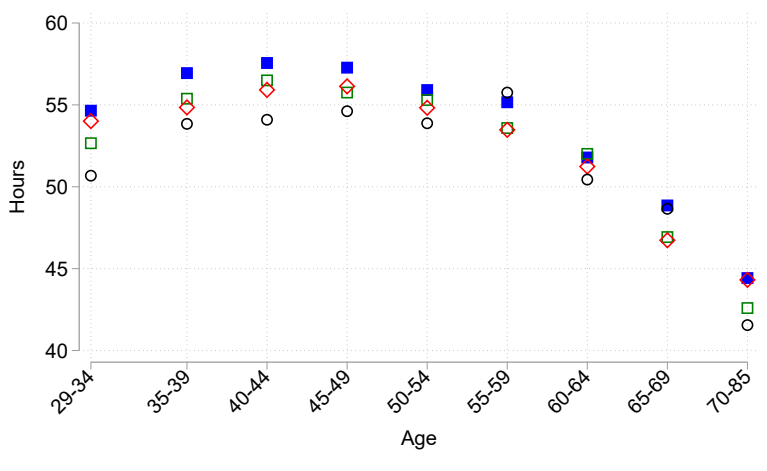

Panel B: Taking New Patients

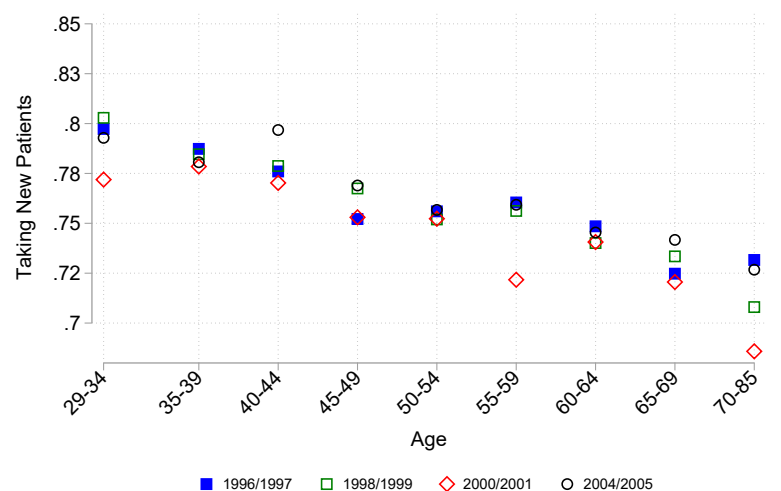

Panel D: Patient Care Hours

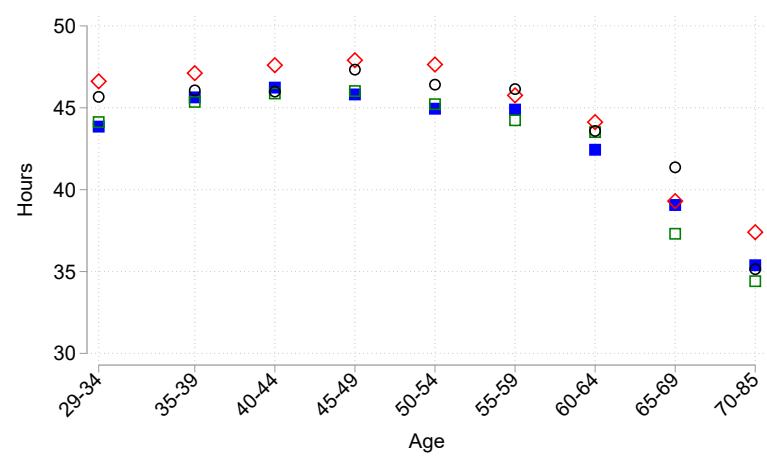

- 1996/1997 $\square$ 1998/1999 $\diamond 2000 / 2001 \quad$ ○ 2004/2005

Panel F: Income

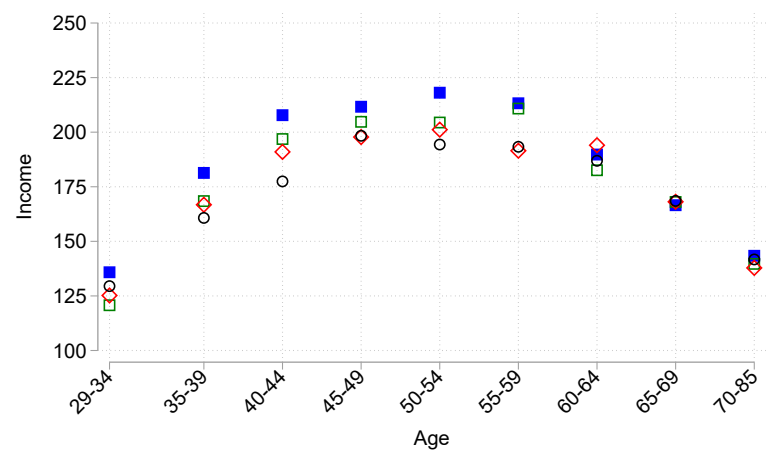

- 1996/1997 口 1998/1999 $\diamond 2000 / 2001 \quad$ ○ 2004/2005

Note: This figure plots average weekly patient care hours, and total weekly hours worked, by age group. Source: Authors' calculations based on data from the Community Tracking Study, 1996/97 wave only (Center for Studying Health System Change, 1999). 


\section{Appendix Table B.1: Practice Type}

\begin{tabular}{lc}
\hline & Count \\
\hline Solo Practice & 12577 \\
Group Practice & 12093 \\
Privately-Owned Hospital & 5021 \\
Medical School/Univ & 3429 \\
Two Physician Practice & 3008 \\
Group Model HMO & 1258 \\
Free-Standing Clinic & 1150 \\
Staff Model HMO & 1134 \\
State/local Government Hospital & 621 \\
State/local Government Clinic & 531 \\
Other & 510 \\
Integrated Health System & 466 \\
PPM & 455 \\
Community Health Center & 367 \\
Independent Contractor & 321 \\
State/local Government Other & 211 \\
PHO & 185 \\
Foundation & 99 \\
MSO & 89 \\
Locum Tenens & 89 \\
Other Insurance & 79 \\
Employer-based Clinic & 74 \\
Total & 43767 \\
\hline \hline
\end{tabular}

This table displays the frequency of different practice types as reported by respondents. Solo practice, twophysician, and group practice make up the large majority of respondents. Source: Authors' calculations based on data from the Community Tracking Study (Center for Studying Health System Change, 1999). 


\section{Appendix Table B.2: Descriptive Statistics by Panel Length}

\begin{tabular}{lcccc}
\hline & \multicolumn{5}{c}{ Number of Times Observed in Panel } \\
& 1 & 2 & 3 & 4 \\
\hline Patient Hours & 44.26 & 44.16 & 44.22 & 45.04 \\
Non-Patient Hours & 9.16 & 8.80 & 9.06 & 8.91 \\
Total Hours & 53.50 & 53.06 & 53.35 & 54.02 \\
Weeks Worked & 46.81 & 47.28 & 47.50 & 47.50 \\
Certified & 0.83 & 0.86 & 0.86 & 0.91 \\
Taking New Patients & 0.75 & 0.74 & 0.73 & 0.74 \\
Income & 167 & 169 & 173 & 187 \\
Age & 46.78 & 47.66 & 49.39 & 49.96 \\
Gender (Male 0 Female 1) & 0.27 & 0.26 & 0.23 & 0.20 \\
Full/Partial Owner & 0.50 & 0.51 & 0.56 & 0.61 \\
Salaried & 0.56 & 0.55 & 0.52 & 0.48 \\
Own-Productivity Affects Compensation & 0.78 & 0.78 & 0.79 & 0.81 \\
N & 11984 & 5522 & 4345 & 1926 \\
\hline \hline
\end{tabular}

This table reports means by the number of survey waves in which the physician appeared. The maximum is four, corresponding to being observed in all four survey waves. Source: Authors' calculations based on data from the Community Tracking Study (Center for Studying Health System Change, 1999). 


\section{B.1 Extensions and Robustness Checks}

This section discusses additional extensions and robustness checks.

\section{B.1.1 Cohorts}

First, we investigate whether cohort trends confound the interpretation of the age profiles from section 3 by plotting the profile of labor supply and investment within each survey wave in Figure B.9. Encouragingly, the age profiles for patient hours, total hours, taking new patients, and income are invariant over time. In contrast, the profile for non-patient hours shifts downwards for all age groups. The late-career decline diminishes slightly, but remains visible in later waves. The percent decline from age 45-49 to age 60-85 in 1996/97 was 18 percent; in 2000/01, it was 12 percent. Finally, board certification propensity increased among older age groups, but remained constant among the young. This indicates higher certification rates among younger cohorts, which would overstate the old-age decline apparent in $1996 / 97$. 


\section{Data Appendix}

\section{C.1 Questionnaire Wording}

\section{Total Labor Supply}

The CTS uses the following wording to elicit total hours of work:

Thinking of your last complete week of work, approximately how many hours did you spend in all medically related activities? Please include all time spent in administrative tasks, professional activities and direct patient care. Exclude time on call when not actually working.

\section{Patient Care Hours}

Immediately after asking about total hours, the following question is asked to measure patient care hours:

Thinking of your last complete week of work, about how many hours did you spend in direct patient care activities? (If necessary, read:) INCLUDE time spent on patient record-keeping, patient-related office work, and travel time connected with seeing patients. EXCLUDE time spent in training, teaching, or research, any hours on-call when not actually working, and travel between home and work at the beginning and end of the work day.

\section{Income}

In each survey wave, respondents are ask to report their income net of expenses for the calendar year preceding the survey wave:

During 1995 [authors' note: or 1997, 1999, 2003], what was your own net income from the practice of medicine to the nearest $\$ 1,000$, after expenses but before taxes? Please include contributions to retirement plans made for you by the practice and any bonuses as well as fees, salaries and retainers. Exclude investment income. (If code "2" in \# A4, read:) Also, please include earnings from ALL practices, not just your main practice. (If necessary, read:) We define investment income as income from investments in medically related enterprises independent of a physician's medical practice(s), such as medical labs or imaging centers. 


\section{Weeks Worked}

Similarly, respondents report their number of weeks worked in the year prior to the survey wave:

Considering all of your practices, approximately how many weeks did you practice medicine during 1995 [authors' note: or 1997, 1999, 2003]? Exclude time missed due to vacation, illness and other absences. (If necessary, read:) Exclude family leave, military service, and professional conferences. If your office is closed for several weeks of the year, those weeks should NOT be counted as weeks worked.

\section{C.2 Variable Construction}

We winsorize each of the hours variables at 105 hours per week. This is equivalent to 15 hour work days seven days a week. This is a fairly extreme upper bound on what a "usual" work week can feasibly look like.

\section{Willingness to Accept New Patients}

The original survey asks:

\section{Medicare:}

Is the practice accepting all, most, some, or no new patients who are insured through Medicare, including Medicare managed care patients?

\section{Medicaid:}

Is the practice accepting all, most, some, or no new patients who are insured through Medicaid, including Medicare managed care patients?

\section{Private:}

Is the practice accepting all, most, some, or no new patients who are insured through private or commercial insurance plans including managed care plans and HMOs with whom the practice has contracts? This includes both fee for service patients and patients enrolled in managed care plans with whom the practice has a contract. It excludes Medicaid or Medicare managed care. 
All, most, some, and none correspond respectively to 4, 3, 2, and 1 in the survey coding. We sum the responses to each of the three questions, subtract 3 , and divide by 9 so that the resulting index ranges from 0 to 1 .

\section{Board Certification}

In the 1996/97, 1998/99, and 2000/01 waves, we use the derived variable BDCERT. Physicians are classified into one of four mutually-exclusive categories: (i) Board certified in any specialty, (ii) Board eligible in any specialty, (iii) Neither, (iv) Not Ascertained. If the physician fell in group (ii), (iii), or (iv) we classified them as not certified.

In the 2004/05 wave, the BDCERT variable was replaced by BDCTANY, which sim-

ply classifies respondents into two mutually-exclusive categories: (i) Board certified in any specialty, (ii) Not board certified in any specialty.

\section{Does Productivity Determine Compensation}

The survey specifically asks physicians if their own productivity influences compensation. We capture this use a binary variable derived from the answer to the following question:

I am now going to read you a short list of factors that are sometimes taken into account by medical practices when they determine the compensation paid to physicians in the practice. For each factor, please tell me whether or not it is EXPLICITLY considered when your compensation is determined:

YOUR OWN productivity (If necessary, read:) Examples include the amount of revenue you generate for the practice, the number of relative value units you produce, the number of patient visits you provide, or the size of your enrollee panel. 